\title{
Mixing in a coastal environment: 1. A view from dye dispersion
}

\author{
James R. Ledwell and Timothy F. Duda \\ Applied Ocean Physics and Engineering Department, Woods Hole Oceanographic Institution, Woods Hole, Massachusetts, \\ USA \\ Miles A. Sundermeyer \\ School for Marine Science and Technology, University of Massachusetts Dartmouth, New Bedford, Massachusetts, USA
}

Harvey E. Seim

Marine Sciences Department, University of North Carolina, Chapel Hill, North Carolina, USA

Received 5 November 2003; revised 28 June 2004; accepted 30 August 2004; published 26 October 2004.

[1] Dye release experiments were performed together with microstructure profiling to compare the two methods of estimating diapycnal diffusivity during summer and fall stratification on the continental shelf south of New England. The experiments were done in 1996 and 1997 as part of the Coastal Mixing and Optics Experiment. During the 100 hours or so of the experiments the area of the dye patches grew from less than $1 \mathrm{~km}^{2}$ to more than $50 \mathrm{~km}^{2}$ [Sundermeyer and Ledwell, 2001]. Diapycnal diffusivities inferred from dye dispersion range from $10^{-6}$ to $10^{-5} \mathrm{~m}^{2} / \mathrm{s}$ at buoyancy frequencies from 9 to 28 cycles/hour. Diffusivities estimated from the dye and those estimated from dissipation rates in the companion paper by Oakey and Greenan [2004] agree closely in most cases. Estimates of diffusivities from towed conductivity microstructure measurements made during the cruises by Duda and Rehmann [2002] and Rehmann and Duda [2000] are fairly consistent with the dye diffusivities. The dye diffusivities would be predicted well by an empirical formula involving shear and stratification statistics developed by MacKinnon and Gregg [2003] from profiling microstructure measurements obtained at the same site in August 1996. All of the measurements support the general conclusion that the diffusivity, averaged over several days, is seldom greater than $10^{-5} \mathrm{~m}^{2} / \mathrm{s}$ in the stratified waters at the site, and usually not much greater than $10^{-6} \mathrm{~m}^{2} / \mathrm{s}$. Severe storms, such as a hurricane that passed over the CMO site in 1996, can dramatically increase the mixing at the site, however. INDEX TERMS: 4568 Oceanography: Physical: Turbulence, diffusion, and mixing processes; 4219 Oceanography: General: Continental shelf processes; 4524 Oceanography: Physical: Fine structure and microstructure; 4544 Oceanography: Physical: Internal and inertial waves; KEYWORDS: dispersion, turbulence, continental shelf

Citation: Ledwell, J. R., T. F. Duda, M. A. Sundermeyer, and H. E. Seim (2004), Mixing in a coastal environment: 1. A view from dye dispersion, J. Geophys. Res., 109, C10013, doi:10.1029/2003JC002194.

\section{Introduction}

[2] Waters over the New England continental shelf become strongly stratified during the summer, with buoyancy frequencies in the pycnocline greater than 10 cycles per hour (cph). This stratification suppresses vertical mixing, so that layers move over one another with little exchange of heat, salt, and dissolved nutrients. Just how much diapycnal mixing occurs is important to the ecology, chemistry, optical properties and dynamics of these waters. Diapycnal diffusivities have been inferred in the past from measurements of turbulent dissipation rates on the shelf, for example by Sandstrom and Oakey [1995], Horne et al.

Copyright 2004 by the American Geophysical Union. 0148-0227/04/2003JC002194\$09.00
[1996], Yoshida and Oakey [1996], Rippeth and Inall [2002], Rehmann and Duda [2000], Duda and Rehmann [2002], and MacKinnon and Gregg [2003]. Measurements of diapycnal diffusivities with tracer release experiments in coastal waters have been rare, particularly in the pycnocline. Houghton and colleagues have estimated near-bottom diffusivities from dye experiments designed to study transport across the foot of the shelf-slope front [Houghton, 1997; Houghton and Visbeck, 1998] and in the bottom boundary layer near a tidal mixing front [Houghton and Ho., 2001; Houghton, 2002]. The present work is an attempt to measure diapycnal diffusivity from dye dispersion and turbulence dissipation rates in the pycnocline on the continental shelf at the same time and space scales.

[3] The experiments were part of the Coastal Mixing and Optics Experiment, sponsored by the Office of Naval 


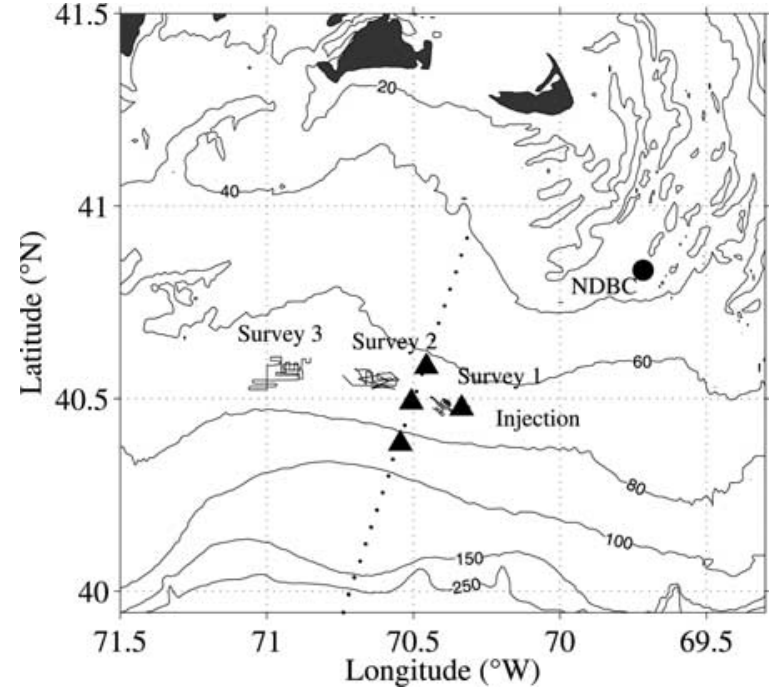

Figure 1. Site. The islands of Martha's Vineyard and Nantucket are at the top. Isobath depths are in meters. Stations for the hydrographic section of Figure 3 are shown as dots. Injection and survey tracks are shown for Experiment 3. Triangles indicate the moorings of Lentz et al. [2003]. Wind data for 1996, shown in Figure 2, are from the central mooring at $40.5^{\circ} \mathrm{N}, 70.5^{\circ} \mathrm{W}$, and wind data for the 1997 experiment, shown in Figure 10 are from NDBC Buoy 44008 (solid circle).

Research and summarized by Dickey and Williams [2001], with many specific results reported in the accompanying articles in that issue. The site of the field work was the continental shelf south of New England, near the 70-m isobath, about midway between the coast and the shelfslope break (Figure 1). The slope of the shelf is about $1 / 1000$ at this location.

[4] Comparisons of turbulent diffusivities inferred from dye dispersion with those inferred from dissipation rates are difficult because of the problem of matching the two measurements in space and time. The approach used in our experiments was to release the dye on an isopycnal surface and sample the initial condition on the first day. The dye was surveyed again 2 and 4 days after the release. On the intervening days, 1 and 3 days after the release, dissipation profiles were taken as near as practical to the estimated location of the dye patch. Dissipation measurements were also sometimes made prior to the dye release and after the final survey. Hundreds of profiles were obtained during each dye release experiment. The results of that work are reported by Oakey and Greenan [2004], which we will refer to as OG04 hereinafter. Here we present the details of the dye release experiments, and compare the results with results from the dissipation measurements. The times and nominal depths of the experiments are listed in Table 1. Section 2 explains the experimental methods. Section 3 presents the results, but not in chronological order. Experiments 3, 4, and 5 are presented first, and then the less definitive Experiments 1 and 2 are presented. We maintain the names for the experiments used by Sundermeyer and Ledwell [2001] for reference to that work. Section 4 presents some statistics of the shear forcing the mixing, and section 5 discusses the findings of the experiment, and compares them with the results of OG04, Rehmann and Duda [2000], and MacKinnon and Gregg [2003], obtained at the same site.

\section{Methods}

[5] The methods used in the present experiments were similar in some respects to those used in long-term tracer release experiments using sulfur hexafluoride [e.g., Ledwell et al., 1998]. However, there are important differences. The duration of the experiments reported here is only 100 hours or so, which is not much greater than the timescale of the tides and internal waves forcing the mixing, nor of the time between mixing events experienced by a given molecule in the fluid. As a result, the definition of a diapycnal diffusivity is problematic, and its determination is less accurate than in the longer experiments. Also, dye surveys here take 10 to 30 hours, during which the size and shape of the dye patch can change significantly.

\subsection{Dyes}

[6] Two dyes were used for the experiments, fluorescein and Rhodamine WT, each with advantages as an ocean tracer. The fluorescence signature of fluorescein is more easily distinguished from the background. Fluorescein is also less than one tenth as expensive as Rhodamine WT. However, because fluorescein decomposes in light, it cannot be used near the surface. Exponential decay rates on the order $0.1 \mathrm{~h}^{-1}$ in water in direct sunlight were found in a number of studies summarized by Smart and Laidlaw [1977]. Consideration of the optical depth typical of the shelf led us to conclude that fluorescein could only safely be considered conservative over 5 days at depths greater than $40 \mathrm{~m}$. The photo decay rate of Rhodamine WT is negligible for 5-day experiments in shallow water.

Table 1. Times and Depths of Experiments

\begin{tabular}{crccccc}
\hline Experiment & \multicolumn{1}{c}{ Dates } & DOY $^{\mathrm{a}}$ & Dye $^{\mathrm{b}}$ & Target, $\sigma_{\theta}$ & $\begin{array}{c}\text { Nominal } \\
\text { Depth, } \mathrm{m}\end{array}$ & $N^{\mathrm{c}}$ cph \\
\hline 1 & $11-14$ Sept. 1995 & $254-257$ & Rhd & 25.20 & 46 & 13 \\
2 & 6-10 Sept. 1996 & $250-254$ & Rhd & 24.06 & 35 & 6 \\
3 & $12-16$ Sept. 1996 & $256-260$ & Flr & 24.30 & 46 & 11 \\
4 & $1-6$ Aug. 1997 & $213-218$ & Rhd & 24.60 & 17 & 16 \\
5 & 7-12 Aug. 1997 & $219-224$ & Flr & 26.14 & 65 & $14-28$ \\
\hline
\end{tabular}

${ }^{\mathrm{a}}$ DOY is Day of Year, defined so that noon on 1 January is DOY 1.5 .

${ }^{\mathrm{b}}$ Rhd, Rhodamine WT; Flr, Fluorescein.

${ }^{\mathrm{c}}$ These differ slightly from those reported by OG04 due to different averaging procedures. A range is given for Experiment 5 because $N$ increased strongly with depth and with time during this experiment. 
[7] The minimum detectable level for Rhodamine WT and fluorescein in clean water with a commercial fluorometer is approximately $0.01 \mu \mathrm{g} / \mathrm{L}$. Neither dye has been found by us to be adsorbed appreciably on mud or organic particulates in lab experiments lasting over a year, despite claims to the contrary in the literature [e.g., Smart and Laidlaw, 1977]. Neither is toxic to those handling it, and both are considered to be safe tracers to use in nearshore ecosystems, lakes, and reservoirs.

\subsection{Release Technique}

[8] Dye was released by pumping from 200-L drums on deck through a garden hose to a simple dispersing system mounted on a frame, which also held a Sea-Bird 9plus CTD. The frame was made neutrally buoyant by attaching floats, and it was towed during the injection behind a weight lowered from a sheave at the waist of the R/V Oceanus. The dye had been mixed with fresh water and isopropyl alcohol to bring its density to within $0.001 \mathrm{~kg} / \mathrm{m}^{3}$ of the water to be tagged, account being taken of the thermal expansion coefficient of the mixture. The flow rate was approximately $0.2 \mathrm{~L} / \mathrm{s}$, with $15 \mathrm{~min}$ required to empty each of four drums, so an hour is normally required for an injection. Trouble with clogged lines caused interruptions in the injection for Experiment 3, the first one described below. The ship maintained a speed through the water of approximately $0.5 \mathrm{~m} / \mathrm{s}$ during the injection.

[9] Data from the CTD were used to keep the release system on a target density surface, within a narrow tolerance. The root mean square density excursion at the injector was equivalent to less than $1 \mathrm{~m}$ when translated to depth through the mean vertical density gradient. The winch operator controlled the depth of the package while watching a display of the density error on a video screen. The pumps were automatically shut off when this density error exceeded a value equivalent to $2 \mathrm{~m}$ in depth in the mean gradient.

\subsection{Dye Sampling System}

[10] A frame housing various sensors was towed at speeds from 0 to $2 \mathrm{~m} / \mathrm{s}$ to sample the dye and hydrographic properties. This frame was designed to sample within $1 \mathrm{~m}$ of the bottom and to be capable of surviving encounters with moored fishing gear. The frame was open, rather than faired, but it was fit with a tail to keep it headed into the flow. The tow point was located near the center of drag and center of mass. Depth was controlled with the winch, while the ship operator maintained a steady speed.

[11] The towed body was fitted with fluorometers for dye and for chlorophyll, an altimeter, a two-axis electromagnetic current meter, and attitude sensors, and data from these instruments were transmitted via the analog channels in the SeaBird system. The $24-\mathrm{Hz}$ CTD data were averaged to $6 \mathrm{~Hz}$ in the SeaBird deck unit, approximately matching the $5.5-\mathrm{Hz}$ flash rate of the fluorometers. CTD data and height above the bottom were available with a lag of less than $1 \mathrm{~s}$ for either manual or automatic control of the winch. Control was usually automatic, with an algorithm that reversed the winch direction at preset pressures. In the case of Experiment 5, near the bottom in 1997, the winch reversed direction at an altimeter reading of $1 \mathrm{~m}$ above the bottom.

[12] Microstructure sensors were also mounted on the towed body, with data taken at high frequency. However, electromagnetic pulses from the fluorometers interfered with the microstructure sensors when the tow sled was submerged in seawater, so useful microstructure data could not be obtained during dye sampling. Separate tows were performed for microstructure during the experiments, and the results were reported by Rehmann and Duda [2000] and Duda and Rehmann [2002].

\subsection{Density Measurement}

[13] The precise measurement of density along the tow track is a crucial element of diapycnal dye dispersal studies. The Sea-Bird 9plus CTD was configured with two pumped sensor pairs. The sensors occasionally suffered fouling and clogging by plankton and debris, but almost always one pair was performing reasonably well. Various lags between the sensors were present in this towed system, and an attempt to correct for them is described in Appendix A.

\subsection{ADCP Measurements}

[14] The ship was equipped with a $150-\mathrm{kHz}$ narrow-band acoustic Doppler current profiler (ADCP) in a pilot experiment in 1995 (Experiment 1) and a $300-\mathrm{kHz}$ broad band ADCP in 1996 and 1997. ADCP data were used to track the dye patches and to determine shear. The velocity at the nominal depth of the target isopycnal surface of the dye release was integrated in real time during the experiments to plan and plot the cruise track in a coordinate system moving with the water beneath the ship. The vertical bin size used for the ADCP velocities was $4 \mathrm{~m}$ in Experiment 1 and $2 \mathrm{~m}$ for the other experiments. The averaging time for the raw velocities was $2.5 \mathrm{~min}$ for Experiment 1 and between 0.5 and $1 \mathrm{~min}$ for the other experiments. The tracking algorithm does not account for vertical excursions of the target isopycnal surface. ADCP velocities were also used to estimate vertical shear and, in combination with the density measurements from the sampling system, the gradient Richardson number.

\subsection{Dye Sampling Strategy}

[15] The strategy of the dye experiments was to release the dye as close as possible to an isopycnal surface, and then measure the subsequent dispersion. The dye was released along a track 1 to $2 \mathrm{~km}$ long rather than as an intense spot to dilute the density anomaly of the dye plume and to make it easier to find the dye for the initial sampling. Three or four drogues were released with the dye to aid tracking. It was found that these were no more helpful in tracking the patch than the integral of the ADCP velocity. The error in both typically increased by about $1 \mathrm{~km} / \mathrm{day}$. The initial surveys began within an hour or two of the injection at a point suggested by the integral of the ADCP velocity and the drogue positions. A line was made through the expected center of the patch, starting from a point estimated to be somewhat outside the patch. If dye was not found on the first attempt, an expanding box pattern was executed until dye was found. Once we passed through the dye, the ship was turned to the left or right for about $1 \mathrm{~km}$ and then turned back again in the direction of the patch. The track was planned relative to the ADCP-integrated position rather than relative to fixed coordinates. Lines were occupied across the patch as we worked our way to the end of the patch, as indicated by the absence of dye along the line. 
Table 2. Statistics, by Survey, for Experiments 3, 4, and 5

\begin{tabular}{cccccc}
\hline Experiment & Survey & $\begin{array}{c}\text { Time After } \\
\text { Injection, } \\
\text { hours }\end{array}$ & $\begin{array}{c}\text { Survey } \\
\text { Duration, } \\
\text { hours }\end{array}$ & $M,{ }^{\mathrm{b}} \mathrm{kg}$ & $N,{ }^{\mathrm{c}} \mathrm{cph}$ \\
\hline 3 & 1 & 15 & 10 & 170 & 10 \\
& 2 & 56 & 22 & 149 & 11 \\
4 & 3 & 102 & 18 & 89 & 11 \\
& 1 & 9 & 12 & 107 & 16 \\
& 2 & 51 & 15 & 183 & 16 \\
5 & 3 & 106 & 27 & 141 & 16 \\
& 1 & 8 & 14 & 96 & 18 \\
& 2 & 55 & 23 & 112 & 19 \\
& 3 & 106 & 30 & 98 & 28 \\
\hline
\end{tabular}

${ }^{\mathrm{a}}$ Time after injection is a mean time for the survey, weighted by the tracer column integrals.

${ }^{b}$ Mass estimated from the survey map; the amount injected in each experiment was $100 \mathrm{~kg}$.

${ }^{\mathrm{c}}$ Buoyancy frequency at the target isopycnal surface, from the mean $\mathrm{P}\left(\sigma_{\theta}\right)$ profile for the survey.

Then we attempted to occupy a line a kilometer or so on the other side of the initial line, working our way to the other end of the patch until no more dye was found. The surveys were done as quickly as possible, but 10 to 14 hours were required for the first surveys, 15 to 23 hours for the middle surveys, centered about 50 hours after injection, and 18 to 30 hours for the final surveys, centered about 100 hours after injection (Table 2). The surveys are idealized as snapshots giving the time evolution of the dye diffusion.

\section{Results}

\subsection{Experiment 3}

[16] A clear view of our methods and results can best be had by reviewing a specific experiment in detail. The example we choose is the third dye experiment of the series (Experiment 3), the second experiment performed in 1996. This was the first experiment which yielded quantitative estimates of diapycnal dispersion, although problems with the dye injection and with sampling were encountered during this experiment that were not present in Experiments 4 and 5. Experiment 3 was performed in the pycnocline between 40 and $50 \mathrm{~m}$ depth from 12 to 16 September 1996. It commenced about 10 days after the passage of Hurricane Edouard had greatly reduced the surface temperature and weakened the stratification [Lentz et al., 2003]. The wind record is shown in Figure 2, and a hydrographic section after the hurricane is shown in Figure 3. A map summarizing the experiment is shown in Figure 4. Approximately $100 \mathrm{~kg}$ of fluorescein were released along the tracks shown in the 0-hour inset in Figure 4, which are broken up due to clogged lines. The target density for the release was $\sigma_{\theta}=$ $24.30 \mathrm{~kg} / \mathrm{m}^{3}$, and the mean pressure at this density surface during injection was approximately $46 \mathrm{dbar}\left(\sigma_{\theta}\right.$ is the potential density anomaly, referenced to the pressure at the surface; its units will be omitted hereinafter).

[17] The first survey of the patch, which commenced shortly after the release, seemed to delimit the tracer patch well, as illustrated in the map of the column integral of the dye in the 15-hour inset of Figure 4. This map, and all others of this type presented here, was made as follows. A column integral is calculated by integrating the dye concentration over the vertical coordinate for each ascending or descending leg of the tow-yo. The time and position at
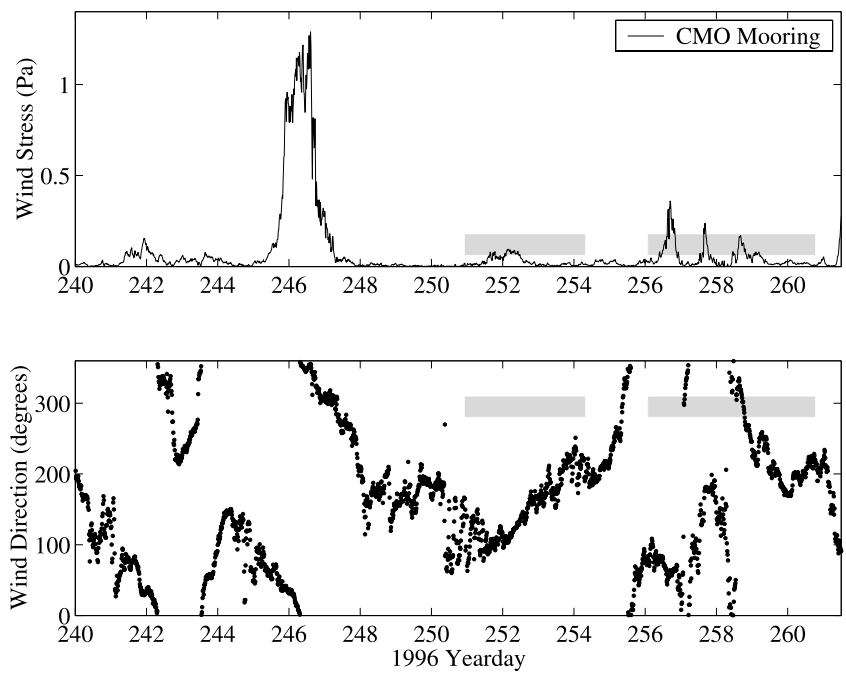

Figure 2. Wind stress and direction in 1996, from the mooring of Lentz et al. [2003]. The intense event around day 246 is Hurricane Edouard. There was a smaller wind event during Experiment 2, performed between days 250 and 254 (6-10 September), and there were three wind events during Experiment 3, days 256-260. Shaded bars indicate the periods of the dye experiments.

which the towed body passed through the target isopycnal surface is assigned to the column integral, though the actual data were collected over a slant path with a horizontally projected length on the order of $200 \mathrm{~m}$. The positions were then shifted to their advected counterparts at a reference

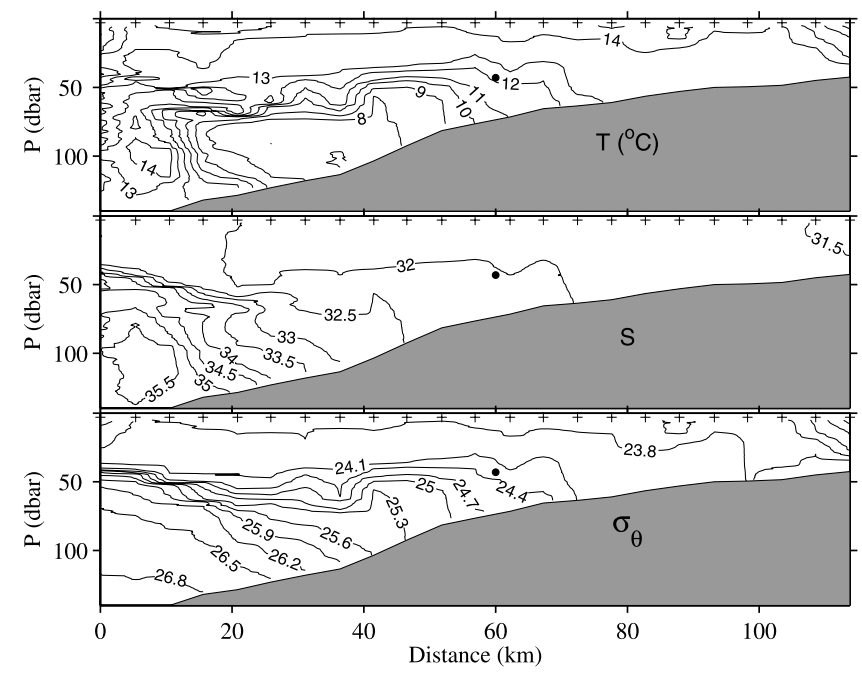

Figure 3. Hydrography across the shelf on 5 September 1996, 3 days after the passage of Hurricane Edouard. Station locations (crosses) are shown as dots in Figure 1. Structure at small scales is due to temporal as well as spatial variability. The dye releases were performed near the $70-\mathrm{m}$ isobath, shoreward of the cold pool seen here within the $8^{\circ} \mathrm{C}$ isotherm, and shoreward of the foot of the shelf-slope front as defined by the maximum salinity gradient along the bottom, which here is at 34 to 34.5 near the 120 -m isobath. The dye release point for Experiment 3 is shown as a dot at $60 \mathrm{~km}$ in each panel. 


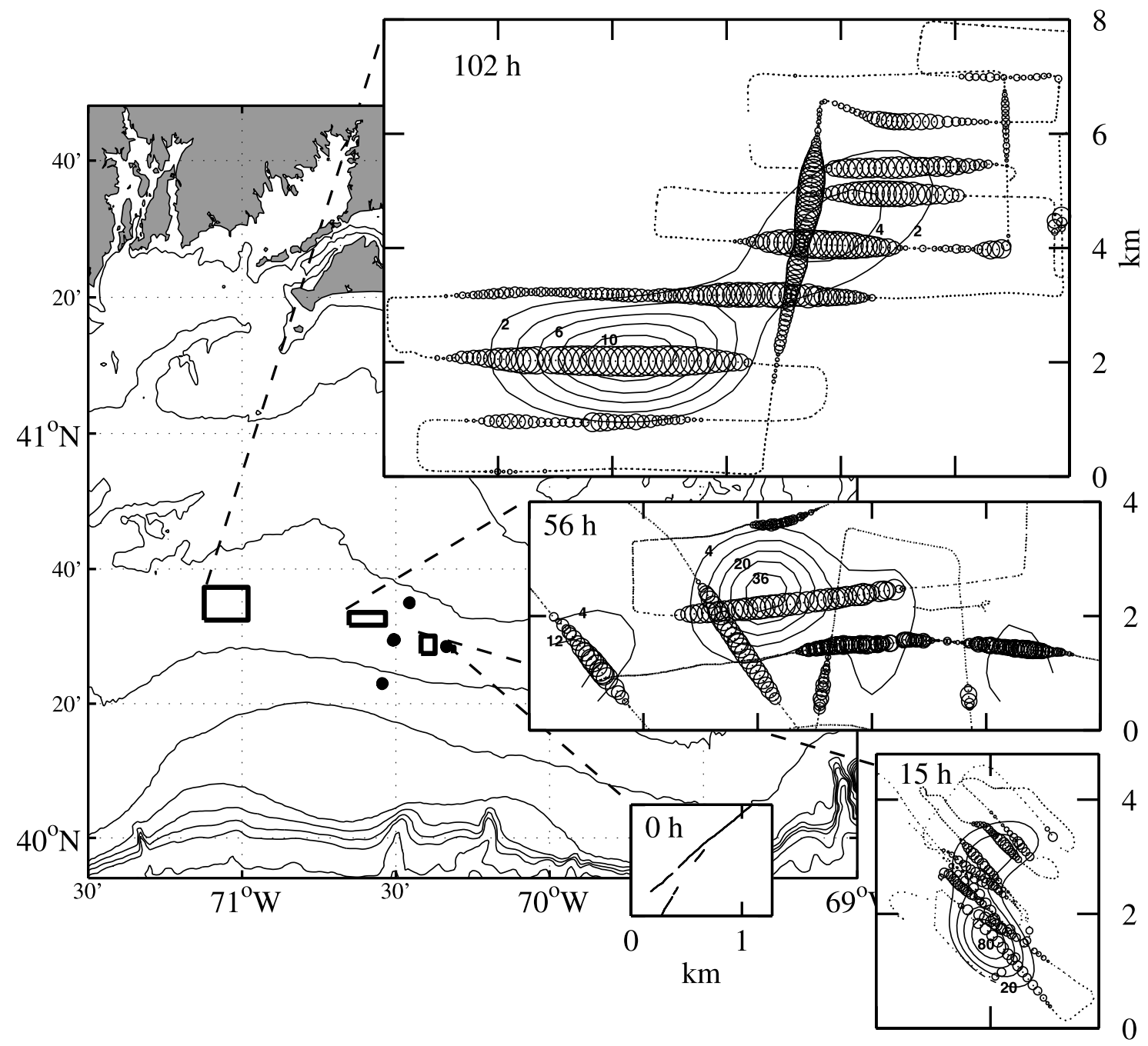

Figure 4. Plan view of Experiment 3. The injection streaks ( 0 hours) were broken up due to clogging of the lines. The survey maps are made by plotting a point for each profile, surrounded by a circle, with a diameter proportional to the logarithm of the column integral. A different concentration scale is used for each survey. Contours in the inset maps show the column integral of dye estimated from an objective mapping routine. The contour intervals are 20,8 , and $2 \mathrm{~kg} / \mathrm{m}^{3}$ for the 15 -hour, 56 -hour, and 102-hour surveys, respectively. The positions within each survey have been transformed to a reference time using the integral of the shipboard ADCP velocity. The survey maps are all to the same scale, while the scale of the injection map at 0 hours is twice as great.

time using the integral of the ADCP velocity in the depth bin containing the mean depth of the target isopycnal surface. A contour map at this reference time is then determined by "objective analysis" [Bretherton et al., 1976], which is the same as "simple kriging" [Kitanidis, 1973]. However, a tracer patch does not satisfy the requirements of the Gauss Markov Theorem which underlie this algorithm, in that the mean and variance of the column integral are not spatially stationary or even well defined, and the variations of the column integral are not normally distributed. The mapping algorithm is used for convenience, with the spatial autocorrelation functions chosen to create maps that seem reasonably smooth. Gaussian functions are used for the autocorrelation function, with a value at zero distance of 0.8 to 0.95 to account for noise at small separation and with a length scale of the same order as the size of the patch for smoothing. For the 15-hour survey in Figure 4, the Gaussian autocorrelation function was set to 0.8 at zero distance with a "standard deviation" of the Gaussian of $1.4 \mathrm{~km}$. The error map that results from the algorithm is of no use in estimating uncertainties, although we do use it to establish a boundary beyond which to ignore the map. A small number of slightly negative values generated by the algorithm within this boundary are subsequently set to zero.

[18] Once a map is made by this procedure, the total amount of tracer represented in the map can be found by summing the column integral in each grid element in the map and multiplying by the area of a grid element. The result for the map shown in the 15-hour inset in Figure 4 is $170 \mathrm{~kg}$ of dye, $70 \%$ more than the $100 \mathrm{~kg}$ injected (Table 2 lists the mass estimated in this way for all the surveys 
discussed herein). The mass estimates for this survey and the others discussed in this paper are not very sensitive to the parameters used in mapping. One source of the overestimate may be that relatively rich areas of tracer in an inhomogeneous patch were sampled. Another source of error is in the positions of the profiles. The procedure of translating these positions with the ADCP integral removes some of the error due to the lack of synopticity of the survey. However, for this procedure to work perfectly the horizontal velocities would have to be uniform over the region of the patch and also over the depth interval occupied by the tracer.

[19] The second survey of Experiment 3, performed roughly 2 days after the first, was less complete and seemed to suffer even more than the first survey from lack of synopticity. There are places where sampling tracks cross, with dye being found in one case but not in the other, for example along the meridional line just east of the main dye patch (Figure 4, 56-hour inset). The integral of the tracer for this survey was $149 \mathrm{~kg}$, again suffering perhaps from inaccuracies in positions as well as the sparseness of the survey. The third survey, about 4 days after the first (Figure 4, 102-hour inset), seemed to delimit the patch again, and this time the mass integral was $89 \mathrm{~kg}$, closer to the amount released.

[20] Individual vertical profiles from these surveys take on a variety of shapes and are centered on a range of isopycnal surfaces. Systematic distortion of the tracer patch seen in individual crossings (Figure 5) illustrates the effect of shear due to baroclinic tides, inertial waves, or mean flow [Sundermeyer and Ledwell, 2001]. In order to study the diapycnal spreading of the dye patch, one must integrate the dye on isopycnals over as much of the patch as possible and then examine the resulting distribution of dye as a function of $\sigma_{\theta}$. This is done by interpolating each concentration profile onto a standard potential density grid, and then averaging over all the profiles as a function of potential density. Because of the uncertainty in positions and the relatively even spacing of the profiles, no attempt was made

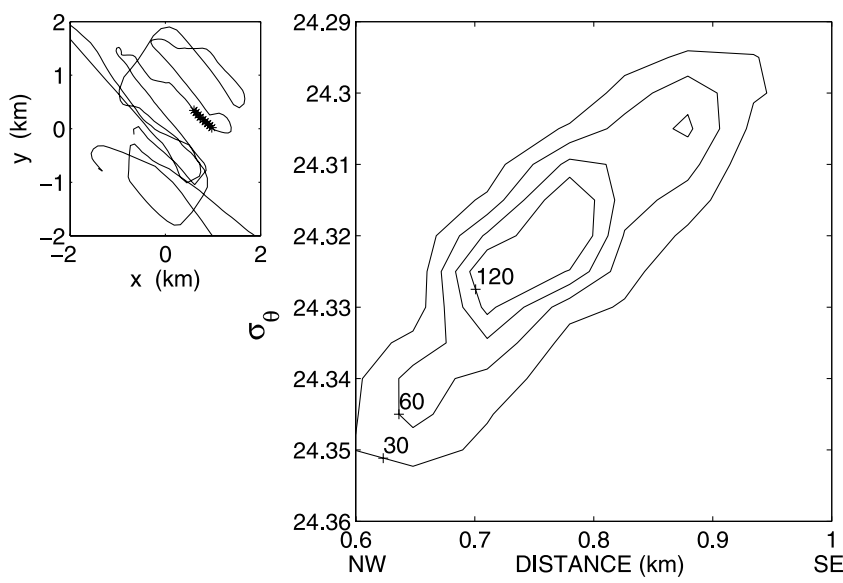

Figure 5. Example of a dye crossing during Survey 1 of Experiment 3. The dye concentration is contoured in $\mu \mathrm{g} / \mathrm{L}$ as a function of $\sigma_{\theta}$. At this stage of the experiment the effect of shear on the dye distribution was pronounced. The hash marks in the inset indicate the location of the section for reference to the 15-hour inset in Figure 4.

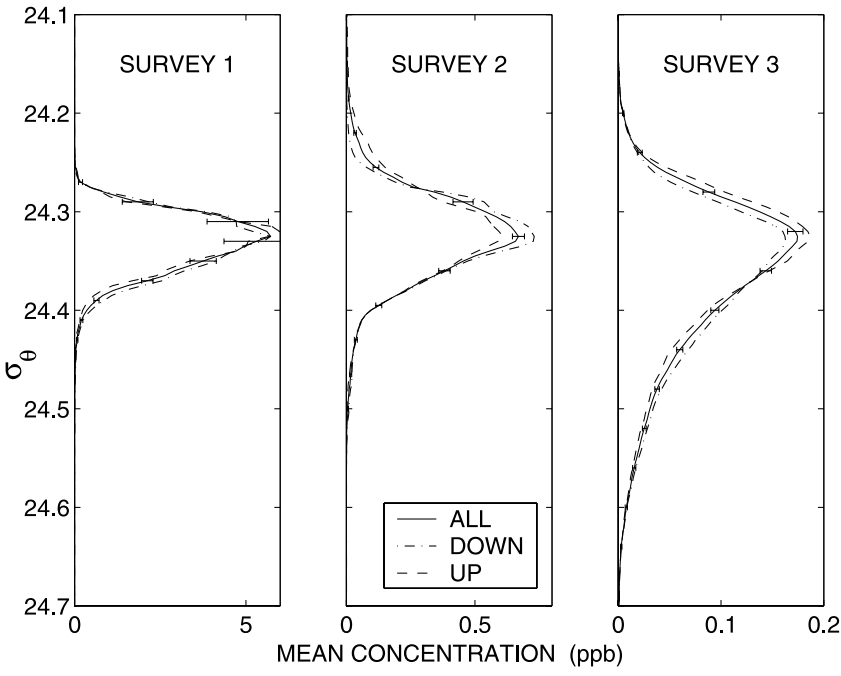

Figure 6. Mean dye profiles for Experiment 3, Surveys 1, 2 , and 3 , as a function of $\sigma_{\theta}$. The difference between the mean of all profiles and the means of the up and down profiles is an artifact of lags in the sensors that remains after the measures described in Appendix A have been taken. The error bars are an attempt to represent the uncertainty in the mean profile due to variability in the shapes of individual profiles, following Ledwell and Bratkovich [1995]. These error bars are relatively large for Survey 1 because of high variability among the small number of high-concentration profiles contributing to the mean. The error bars do not encompass the spread between the mean "up" and "down" profiles for Surveys 2 and 3 because of relative consistency of shape within these sets of profiles and the large number of profiles contributing to the means.

to account for variations in the spacing of the profiles. Each profile received the same weight.

[21] The average profiles for the three surveys are shown in Figure 6, which also shows the means of the downward and the upward legs of the tow-yo separately. These mean profiles differ from one another mostly because the relative lags in the sensors have not been perfectly accounted for (see Appendix A). The error bars on the mean of all the profiles indicate the uncertainty due to the variance among the shapes of the profiles, following Ledwell and Bratkovich [1995]; they do not incorporate the uncertainty from missed tracer. Uncertainty in the diapycnal diffusivity from either the sensor lags or from observed shape variance within a survey is small compared with the variations in the diapycnal diffusivity from one 2-day period to another and from one density layer to another.

[22] There are several problems with the middle survey for this experiment. We already mentioned that it was less complete, spatially, which is the most serious problem. Also, it was necessary to add 0.013 to the salinities for this survey to make the Survey 2 tracer peak appear at the same value of $\sigma_{\theta}$ as the peaks for the other two surveys. This adjustment of the salinity also makes the temporal progression of the tracer distribution in salinity space monotonic, as seen in the middle panel of Figure 7, but bottle samples to confirm such an adjustment are lacking. A further complication is that this survey was performed partly with a small CTD cage at 


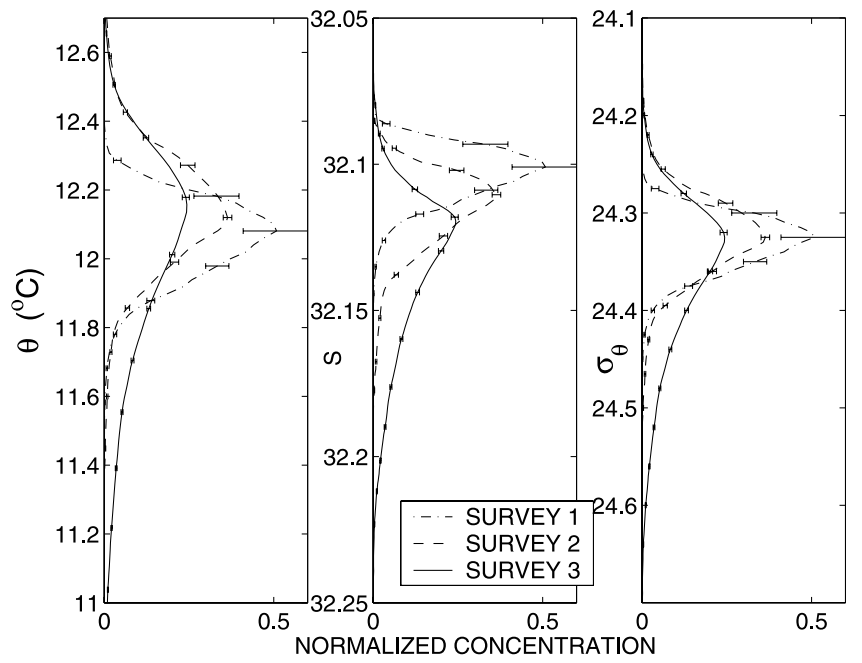

Figure 7. Mean normalized vertical profiles from Experiment 3 , as a function of $\theta, S$, and $\sigma_{\theta}$. A calibration shift of 0.013 for $S$ was necessary for Survey 2 to keep the peak of its mean profile near the same value of $\sigma_{\theta}$ as for the other two surveys. The error bars are as in Figure 6.

relatively low speed and different lag characteristics and partly with the towed body at faster speed. Thus the middle survey should be viewed as less accurate than the other two.

[23] The peak concentration in Figure 6 appears at $\sigma_{\theta}=$ 24.32 , slightly greater than the injection value of 24.30 . Some of this difference may be due to a difference between the salinity calibrations for the injection system and the sampling system, and some may be due to a drop of less than $30 \mathrm{~cm}$ of the dye plume due to a density anomaly in the mixture injected. However, the Survey 1 profile is used as the initial condition, so this difference between the target and actual density does not affect the interpretation of the results.

[24] Mean profiles from all three surveys are shown in Figure 7 as functions of potential temperature, salinity, and $\sigma_{\theta}$. Expression of the diapycnal dispersion of the tracer in terms of a diapycnal diffusivity requires transformation of the mean profiles into a vertical spatial coordinate. The most sensible way to do this in the present context is through a representative mean vertical profile of $\sigma_{\theta}$. Figure 8a shows the mean $\sigma_{\theta}$ profile for each of the three surveys. The stratification was weaker during the first survey than during the second and third surveys. We use the mean profile from the third survey to make our transformation between $\sigma_{\theta}$ and pressure and hence to plot concentration versus pressure in Figure $8 \mathrm{~b}$, because the third survey covered far more area than the first survey and because there is little change between the second and third surveys. The dye profiles have been normalized to have equal areas when integrated over this pressure.

[25] Figure 8b gives the impression that the tracer mixed mostly upward during the first 2 days, between Survey 1 and Survey 2, and then mostly downward during the next 2 days. It is difficult to say how much of this apparent intermittency is due to imperfections in the surveys, especially Survey 2 . However, it is true that the deep tail for Survey 3 is found in most transects across the patch and is not the result of an isolated strong deep plume of tracer. This consistency is reflected in the small error bars in the deep tail for Survey 3. So it appears that mixing in the patch occurred during the first 2 days in the 3-m layer above the peak, and then during the next 2 days in the 7-m layer below the peak, suggesting strong vertical variability of the diffusivity when averaged over 2 days. Nevertheless, it also appears that during each period and within each layer the vertical tracer distribution is fairly uniform over a scale of several square kilometers, suggesting either spatial correlation of mixing events in the horizontal or rapid lateral homogenization of the effect of mixing at these scales. How brief in time the mixing was, within the 2 days, is a question to which we shall return in section 5.1, when we compare the dye results with those from the microstructure measurements.

[26] The depth-dependent diapycnal diffusivity $K_{\text {dye }}(z)$ that would mix the dye from the Survey 1 profile to the Survey 3 profile in Figure $8 \mathrm{~b}$ has been estimated with the aid of a one-dimensional (1-D) numerical model. Horizontal integration of the 3-D advection-diffusion equation over a region of constant area encompassing the patch gives the following equation:

$$
\frac{\partial C}{\partial t}+\frac{\partial(C w)}{\partial z}=\frac{\partial}{\partial z}\left(K_{\mathrm{dye}} \frac{\partial C}{\partial z}\right),
$$

where $C$ is the isopycnally averaged concentration, $t$ is time, $z$ is the distance above the $\sigma_{\theta}=24.32$ surface, where the peak appears in Figure 7, and $w$ is the mean velocity perpendicular to the isopycnal surfaces, which are assumed to be parallel if internal waves and other high-frequency processes are filtered out. $K_{\mathrm{dye}}$ and $w$ are assumed to be independent of position on an isopycnal surface. In the model we assume that the diapycnal diffusivity for heat $K_{T}$ is equal to that of salt $K_{S}$, and that both are the same as $K_{\text {dye }}$,
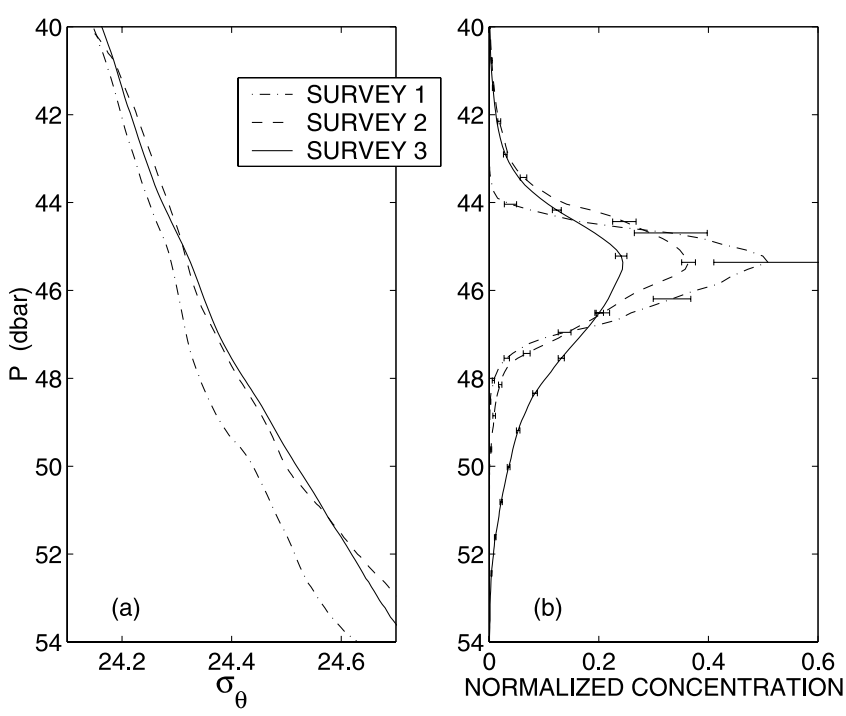

Figure 8. Mean $\sigma_{\theta}$ and dye profiles for Experiment 3 . Data were averaged on isopycnal surfaces rather than isobaric surfaces for these plots. (a) Change in the mean density gradient from one survey to the next. (b) The mean $\mathrm{P}\left(\sigma_{\theta}\right)$ curve for Survey 3 was used to convert the mean dye profile into pressure coordinates. 
and we use the unsubscripted symbol $K(z)$ for them all. With these assumptions the equation for density averaged over the region is

$$
\frac{\partial \sigma_{\theta}}{\partial t}+w \frac{\partial \sigma_{\theta}}{\partial z}=\frac{\partial}{\partial z}\left(K \frac{\partial \sigma_{\theta}}{\partial z}\right)
$$

or, dividing by $\partial \sigma_{\theta} / \partial z$,

$$
w-\left.\frac{\partial z}{\partial t}\right|_{\sigma_{\theta}}=\frac{\partial K}{\partial z}+K\left(\frac{\partial \sigma_{\theta}}{\partial z}\right)^{-1} \frac{\partial^{2} \sigma_{\theta}}{\partial z^{2}}
$$

The left-hand side of equation (3) is just the vertical velocity relative to isopycnal surfaces, which we shall define as $w^{*}$.

[27] The long deep tail in the Survey 3 profile calls for a diffusivity that increases strongly with depth in the few meters beneath the peak of the distribution. After trying a few functional forms for $K(z)$, we settled on the following hyperbolic tangent function:

$$
K=K_{1}+\frac{K_{2}}{2}\left[1-\tanh \left(\frac{z-z_{0}}{h}\right)\right] .
$$

By running the model forward iteratively we obtained the least squares fit to the initial and final profiles shown in Figure 9, for the following values of the parameters in this equation: $K_{1}=1.2 \times 10^{-6} \mathrm{~m}^{2} / \mathrm{s}, K_{2}=9 \times 10^{-6} \mathrm{~m}^{2} / \mathrm{s}, z_{0}=$ $-2.5 \mathrm{~m}, h=2 \mathrm{~m}$.

[28] In the resulting profile for $K(z)$, shown in the inset in Figure 9, $K(z)$ is just a little larger than $10^{-6} \mathrm{~m}^{2} / \mathrm{s}$ above $z=0$, but must increase to approximately $10^{-5} \mathrm{~m}^{2} / \mathrm{s}$

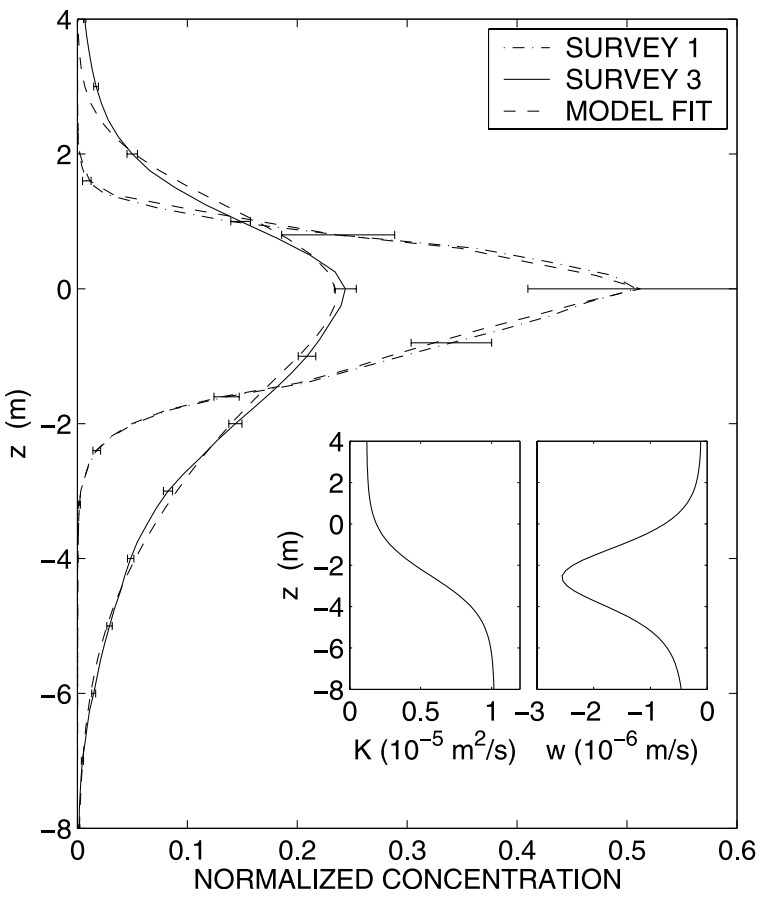

Figure 9. Model fit for the evolution of the dye profile from Survey 1 to Survey 3, Experiment 3. Here $z$ is the height above the $\sigma_{\theta}$ surface where the initial peak was found. The insets show the strong dependence of $K$ on $z$, and consequently of $w^{*}$ on $z$, required to obtain this fit.
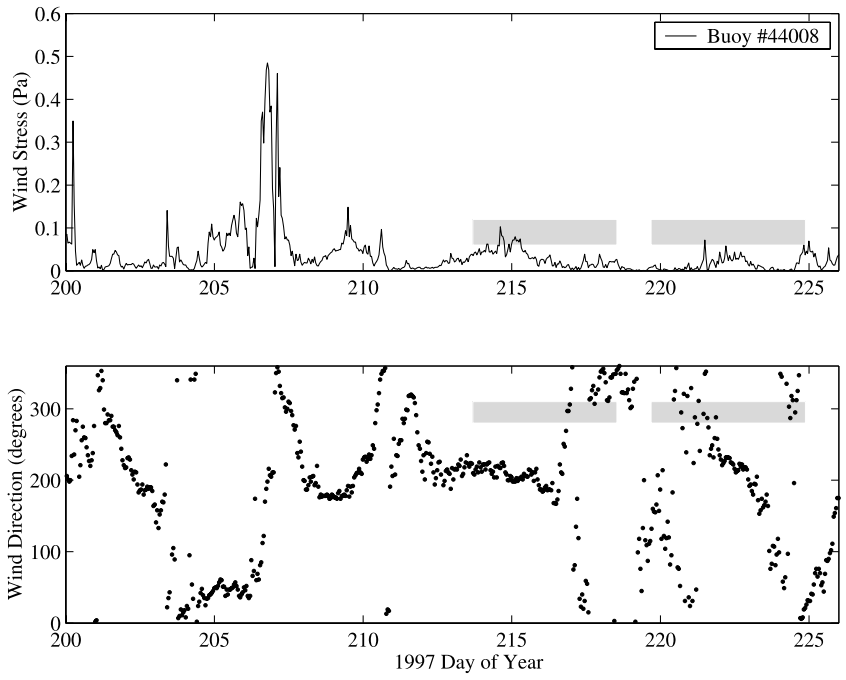

Figure 10. Wind stress and direction at NDBC Buoy 44008 during the August 1997 cruise. The periods of Experiments 4 and 5 are indicated by the shaded bars. The buoy location is shown in Figure 1.

between $z=0$ and $z=-5 \mathrm{~m}$ in order to create the long tail of the Survey 3 profile. Also shown in an inset in Figure 9 is the diapycnal velocity $w^{*}$, which is dominated by the $\partial K / \partial z$ term in equation (2), and so is negative, with a magnitude of more than $2 \times 10^{-6} \mathrm{~m}^{2} / \mathrm{s}$ at $z=z_{0}$.

[29] This strong depth dependence of $K$ and $w^{*}$ is most likely peculiar to the time and place of the experiment; that is, such profiles for $K(z)$ and $w^{*}(z)$ are not expected to persist. As discussed earlier, the Survey 2 profile, as imperfect as it is, suggests that there was a shift in the site of strongest mixing from above $z=0$ for the first 2 days to below $z=0$ for the last 2 days, and the curve fitting exercise suggests how much greater the mixing was during this second period. We conclude that $K_{\text {dye }}$ for this experiment was $5 \pm 4 \times 10^{-6} \mathrm{~m}^{2} / \mathrm{s}$, where the uncertainty reflects variability of $K_{\text {dye }}$ with depth and time during the 4-day time period more than imperfections in sampling.

[30] Note that in this instance $K_{\text {dye }}$ seemed to increase with depth, while $N$ also increased with depth, from less than $10 \mathrm{cph}$ between 40 and $44 \mathrm{dbar}$, to more than $12 \mathrm{cph}$ between 47 and 51 dbar (Figure 8a shows the density profile). The peak of the tracer profile was near 45.5 dbar, about $25 \mathrm{~m}$ above the bottom. Hence, in this realization, $K_{\text {dye }}$ seems to have increased with increasing stratification. This behavior illustrates the hazards of inferring relationships between diffusivity and buoyancy frequency from small data sets.

\subsection{Experiment 4}

[31] Experiment 4 was performed with Rhodamine WT at about $17 \mathrm{~m}$ depth during summer stratification, 1-6 August 1997. The location was the same as for Experiment 3, although the $\mathrm{CMO}$ mooring array had been recovered by the time of this experiment. The flow of the shelf water during this cruise was not toward the west as it usually is, perhaps due to relaxation from a storm with strong northerly and then northwesterly winds that had passed through the region about a week before the experiment started (Figure 10). The foot of the shelf-slope front was at the $70-\mathrm{m}$ isobath just 


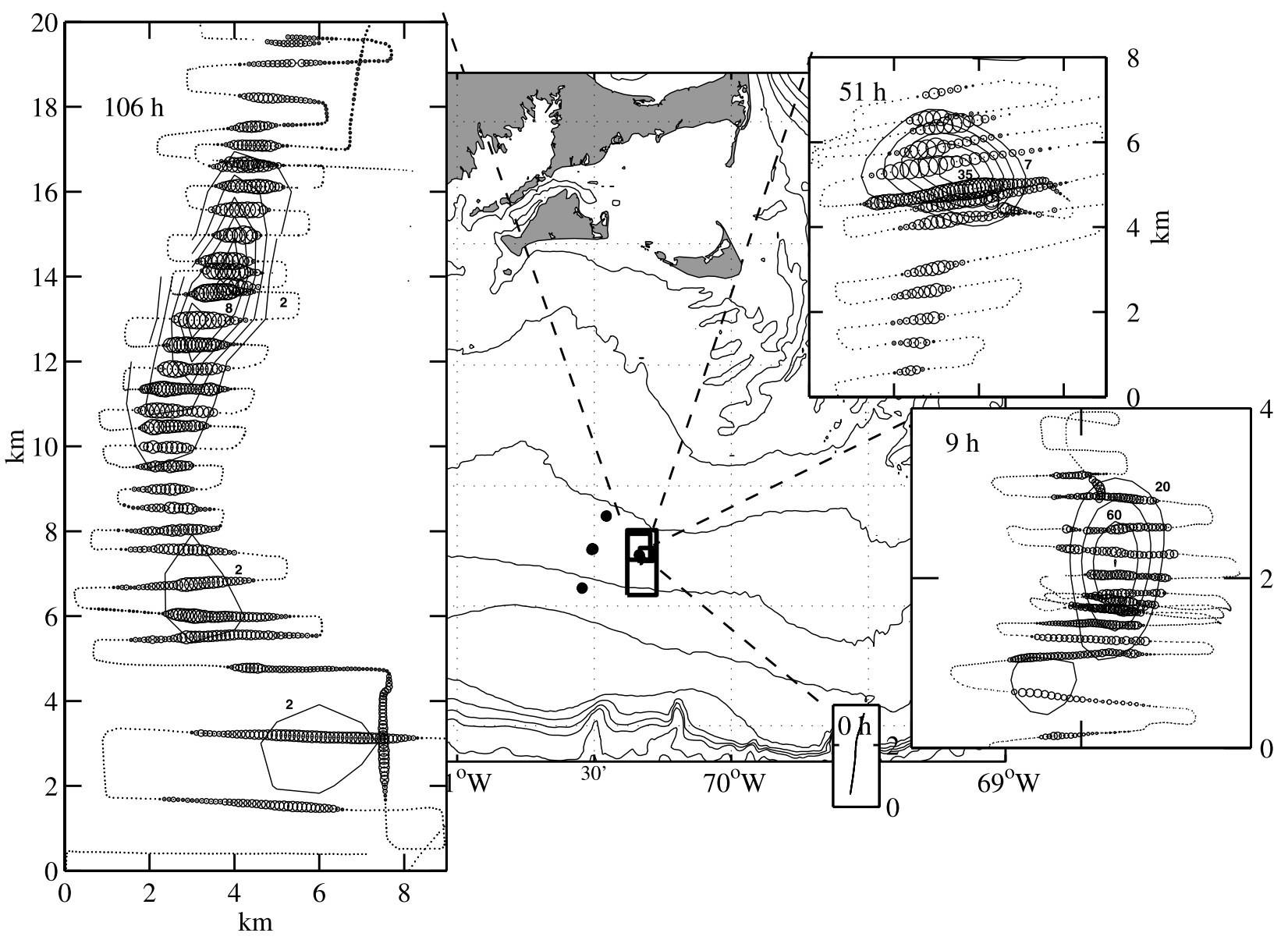

Figure 11. Plan view of Experiment 4. The survey maps are made as for Figure 4. The 9-hour inset has been expanded by a factor of 2 for clarity. The contour intervals are 20,7 , and $2 \mathrm{~kg} / \mathrm{m}^{3}$ for the 9-hour, 51-hour, and 106-hour surveys, respectively. In this experiment the injection was continuous, and inconsistencies in the dye finds where tracks cross are less apparent.

prior to the experiment, and the subtidal velocity was very small. After the end of this first experiment a flow to the east developed, and associated with this was an onshore Ekman flow near the bottom layer, bringing the foot of the shelf-slope front even farther onshore. These effects will be seen when we discuss Experiment 5. Weather conditions during the cruise were calm; the wind stress was much less than $0.1 \mathrm{~Pa}$ for most of it (Figure 10).

[32] The release was uneventful, with $100 \mathrm{~kg}$ of dye injected in a single streak, shown in the 0-hour inset in Figure 11 along with the lateral evolution of the patch. All three surveys in this experiment produced well-delimited tracer patches. The mass integral $M$ for the first survey was $107 \mathrm{~kg}$, close to the amount released. However, the integral for the second survey was $183 \mathrm{~kg}$, and that for the third was $141 \mathrm{~kg}$ (Table 2). Again, these discrepancies from the amount released must be attributed to inhomogeneity in the tracer patch and to lack of coherence in the horizontal velocity field over the region occupied by the patch, so that the displacements inferred from integration of the velocity at the ship are in error.

[33] The results for the mean dye profiles are shown as functions of potential temperature, salinity, and $\sigma_{\theta}$ in Figure 12. The upper tail of the dye profile as a function of salinity is double valued for Survey 3 . This can only be due to

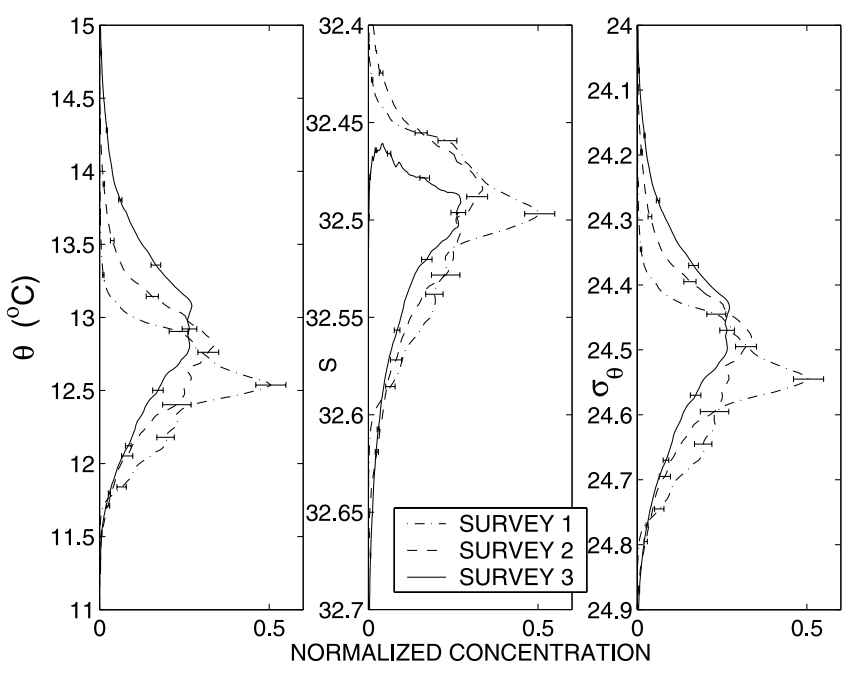

Figure 12. Mean dye profiles for Experiment 4, as a function of $\theta, S$, and $\sigma_{\theta}$. The layer containing the dye seemed to be heated by the Sun during this experiment. The doubling over of the upper tail of the dye profile as a function of $S$ for Survey 3 must be due to a convergence of salinity on isopycnal surfaces in the upper part of the layer. 


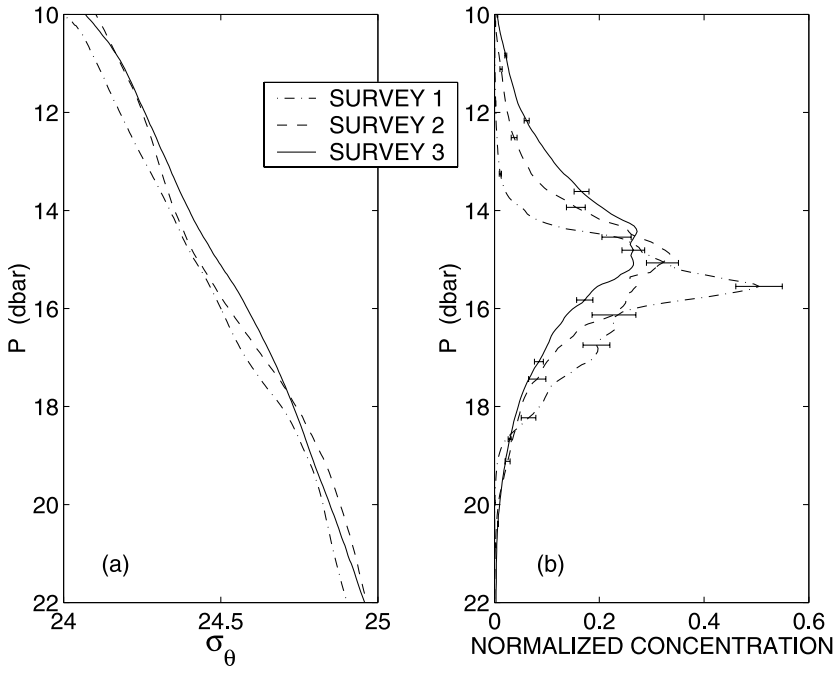

Figure 13. Mean $\sigma_{\theta}$ and dye profiles for Experiment 4. As for Experiment 3, the mean $\mathrm{P}\left(\sigma_{\theta}\right)$ curve for Survey 3 was used to convert the mean dye profile into pressure coordinates in the Figure 13b.

a convergence of relatively salty water into the region of the dye patch on isopycnal surfaces in the upper layers. Temperature dominates the density profile, so that the dye profile remains single valued as a function of temperature and density. The mean density profile from Survey 3 was used to transform the mean dye profiles into pressure coordinates (Figure 13).

[34] The tracer peak migrated to higher temperature and lower density, while remaining at the same salinity, as the experiment went on. We attribute this migration to absorption of solar radiation by phytoplankton and other particles in this layer, and by the dye itself. We constructed a simplified model for the radiative flux as a function of depth in the layer occupied by the dye,

$$
I=I_{0} e^{-\int_{z}^{0} b d z^{\prime}},
$$

where $I_{0}$ is the flux penetrating the surface and where the effective absorption coefficient $b$ is estimated from measurements of absorption coefficients for summertime conditions at the site by Sosik et al. [2001], and from the absorption spectrum for Rhodamine WT, as

$$
b=(0.1+0.1 \mathrm{Chl}+0.06 C) \mathrm{m}^{-1},
$$

where $\mathrm{Chl}$ is the chlorophyll concentration and $C$ is the mean dye concentration in the dye patch, both in $\mu \mathrm{g} / \mathrm{L}$, and both functions of depth.

[35] Although Chl increases with depth through the dye layer (Figure 14, inset) and $C$ has a sharp peak in this layer, the exponential attenuation of the flux dominates all else to make the heating rate, given by $d I / d z$, decrease monotonically with depth (Figure 14, inset) except within $1 \mathrm{~m}$ of the dye peak during the early stages of the experiment. Given the crudeness of the model and the absence of radiation measurements during the experiment, we simply use the dye and chlorophyll profiles from the third survey to give us the heating profile.
[36] This heating profile was incorporated in the onedimensional model used to estimate diapycnal diffusivity, thus introducing a contribution to the diapycnal velocity given by solar heating of the fluid. The density profile was approximated as being in steady state (see Figure 13a), which would mean that any vertical divergence of fluid out of a density layer is compensated by along-isopycnal convergence from outside the dye patch, keeping the layer thickness constant. The diffusivity, taken independent of depth in this case, and the value of $I_{0}$ were both varied to find the least squares fit to the initial and final profiles (Figure 14). The resulting estimate of $K_{\text {dye }}$ is $1.8 \pm 0.4 \times$ $10^{-6} \mathrm{~m}^{2} / \mathrm{s}$, and the value required of $I_{0}$ to give the observed shift upward of the dye was $225 \pm 25 \mathrm{~W} / \mathrm{m}^{2}$, which is consistent with fair weather in August. The uncertainty limits here are within the context of the least squares fit to the normalized profiles, and do not include uncertainties due to dye not found, for example.

[37] The radiation profile has a modest positive effect on dispersing the dye in density space. If we had ignored the vertical gradient in the heat source and simply shifted the final profile so that it was centered at the same depth as the initial profile, then we would have estimated a value of $2.4 \times 10^{-6} \mathrm{~m}^{2} / \mathrm{s}$ for $K_{\text {dye }}$. The buoyancy frequency was approximately $16 \mathrm{cph}$ for this experiment, not changing significantly in the depth range occupied by the dye.

\subsection{Experiment 5}

[38] In the last dye experiment, $100 \mathrm{~kg}$ of fluorescein dye were released near the bottom at the CMO site (Figure 15). At the time of the release the along-isobath current was

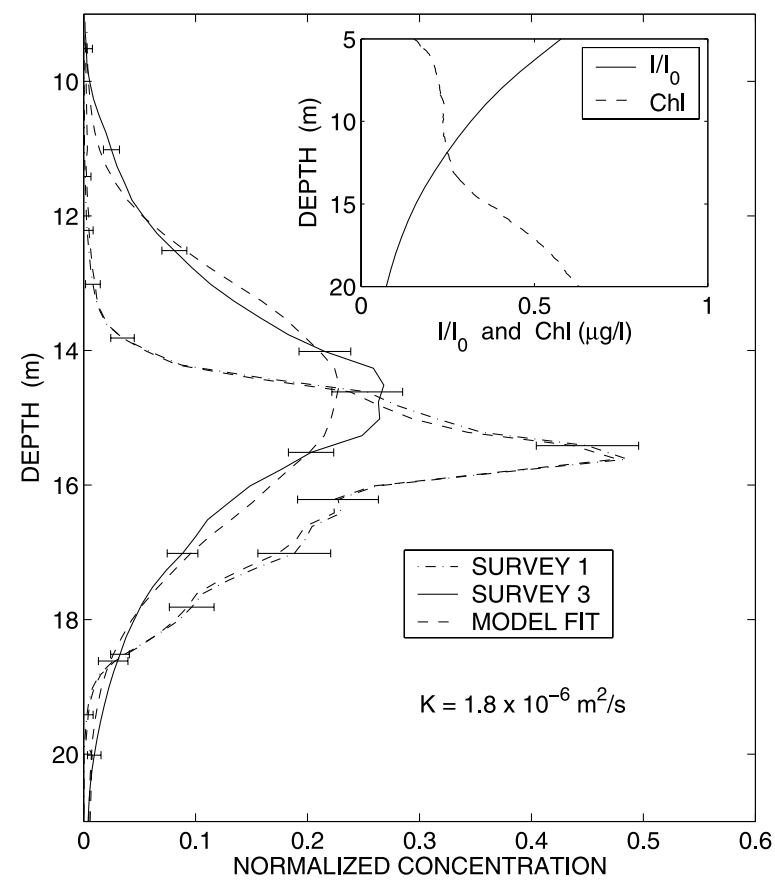

Figure 14. Model fit for the evolution of the dye profile from Survey 1 to Survey 3 for Experiment 4. The depth is for the mean $\sigma_{\theta}$ profile for Survey 3. The inset shows the chlorophyll profile $\mathrm{Chl}$ and the radiation flux profile $I / I_{0}$. The best fit, shown here, was for $K=1.8 \times 10^{-6} \mathrm{~m}^{2} / \mathrm{s}$ and $I_{0}=225 \mathrm{~W} / \mathrm{m}^{2}$. 


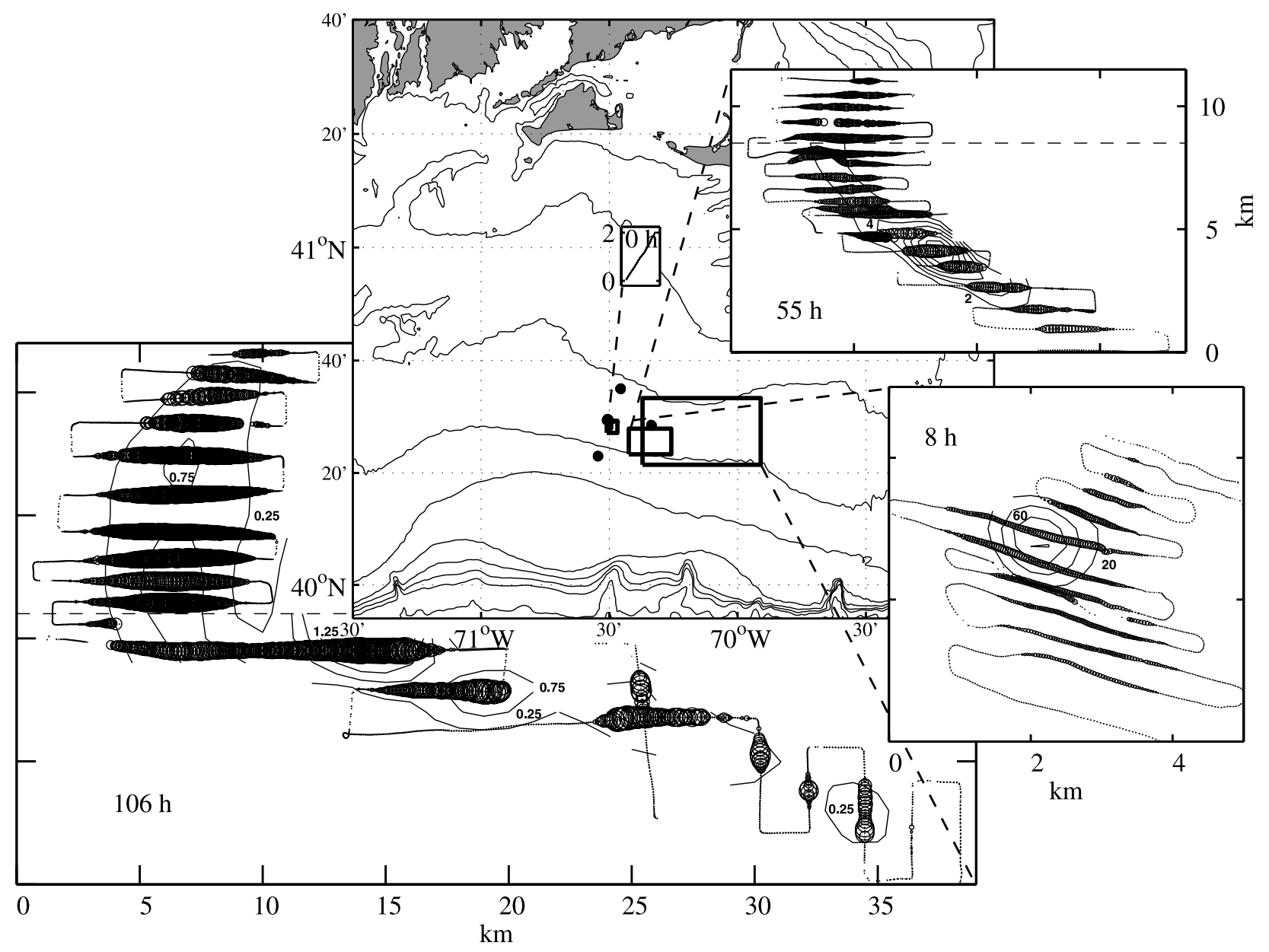

Figure 15. Plan view of Experiment 5. The survey maps are made as for Figure 4. The 8-hour inset has been expanded by a factor of 3 for clarity. The contour intervals are 20,2 , and $0.25 \mathrm{~kg} / \mathrm{m}^{3}$ for the 8 -hour, 55-hour, and 106-hour surveys, respectively. The dashed lines in the 55-hour and 106-hour panels separate the bottom-attached part of the patch, to the north, from the interior part of the patch, to the south.

starting toward the east and the foot of the shelf-slope front had moved over the site, as mentioned above. Temperature, salinity, and density all increased with depth from $50 \mathrm{~m}$ to the bottom, which was at approximately $72 \mathrm{~m}$ (Figure 16). The release was on the $\sigma_{\theta}=26.13$ surface, which was about $5 \mathrm{~m}$ above the bottom during the injection, but which shoaled during the experiment as warm, salty water from the slope continued to move shoreward under the main dye patch. The vertical profiles of temperature and salinity were potentially unstable to double diffusive convection, with a density ratio, defined as

$$
R_{\rho}=\frac{\alpha(\partial \theta / \partial z)}{\beta(\partial S / \partial z)}
$$

increasing from 0.31 to 0.37 between Survey 1 and 3 in the layer of strong gradients between $\sigma_{\theta}=26.1$ and 26.5. In equation (7), $\alpha$ is the thermal expansion coefficient, $\theta$ is the potential temperature, and $\beta$ is the fractional increase of density with salinity.

[39] The total amount of dye estimated from maps of the patches for each survey was close to the amount released
(Table 2), although this seems fortuitous, especially since the third survey did not delimit the patch completely. Much of the dye remained off the bottom and was swept eastward at a mean speed of approximately $12 \mathrm{~cm} / \mathrm{s}$. Some of the dye, however, mixed downward into an onshore flow in a stratified bottom boundary layer (BBL). The parts of the patch north of the dashed lines in the 55-hour and 106-hour insets in Figure 15 are attached to the bottom. The sharp gradient between $\sigma_{\theta}=26.1$ and 26.5 in Figure 16c marks the lid of this boundary layer. Figure 17 shows the two parts of the dye patch viewed from the west, the northern part hugging the bottom and the southern part lying above the bottom. The onshore flow in the BBL crossed isopycnal surfaces that intersected the bottom, and so is associated with a convergence of buoyancy flux from above. Dye in this bottom flow probably mixed at first into waters of greater density to reach the bottom layer, but once in the bottom flow, the water it traveled with became less dense. At the extreme onshore tip of the dye patch in the final survey, there is dye at $\sigma_{\theta}<25.8$. In fact, virtually all of the dye at $\sigma_{\theta}<25.85$ was found in the northern part of the patch attached to the bottom. 

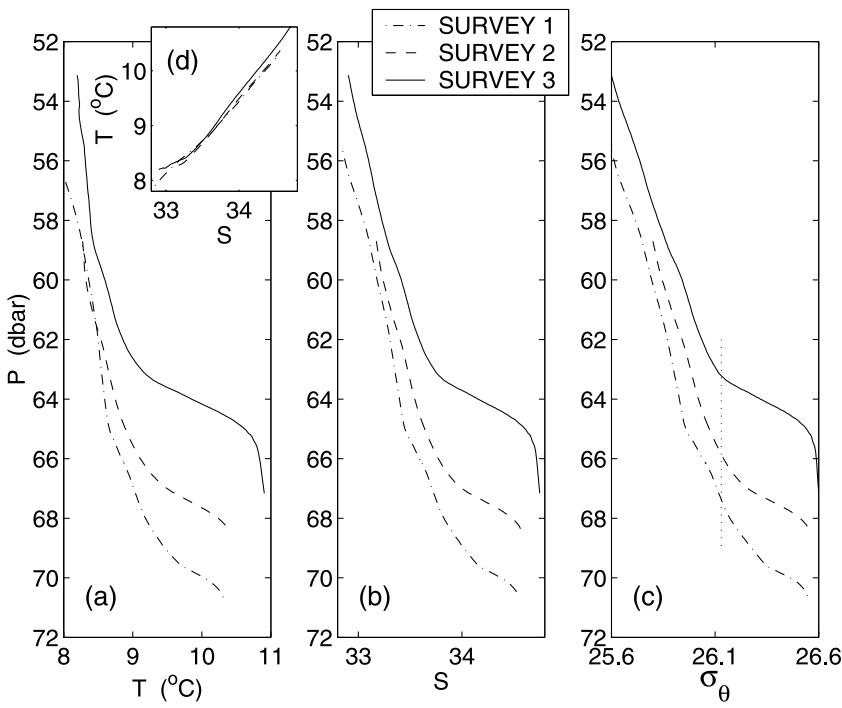

Figure 16. Profiles of temperature, salinity and $\sigma_{\theta}$ for Experiment 5, Surveys 1, 2 and 3. Data were averaged on isopycnal surfaces rather than isobaric surfaces for these plots. The dye was released at $\sigma_{\theta}=26.13$, indicated by the dotted line in Figure 16c, and just above the layer where the gradients were large and increasing during the experiment. Figure $16 \mathrm{~d}$ shows $\mathrm{T} / \mathrm{S}$ plots for the three surveys.

[40] The flow and buoyancy budget in the bottom boundary layer is beyond the scope of this paper, though we note that Rehmann and Duda [2000] estimated a diapycnal diffusivity for heat of $3 \times 10^{-6} \mathrm{~m}^{2} / \mathrm{s}$ from this flow. What concerns us here is diffusion of the dye in the interior of the fluid, away from the BBL, i.e., of the main patch that was swept eastward. Figure 18 shows the differential mass inventory, which we call $X$, of the detached part of the patch as a function of $\sigma_{\theta} . X$ has the dimensions of mass since we have artificially made $\sigma_{\theta}$ dimensionless; the integral of the curve in Figure 18 over $\sigma_{\theta}$ gives the mass in the detached part of the patch. All of the dye was included for Survey 1 in this figure, since the deep dye had not yet reached the bottom and been carried onshore in the BBL. In Survey 2 all of the dye north of the dashed line in the

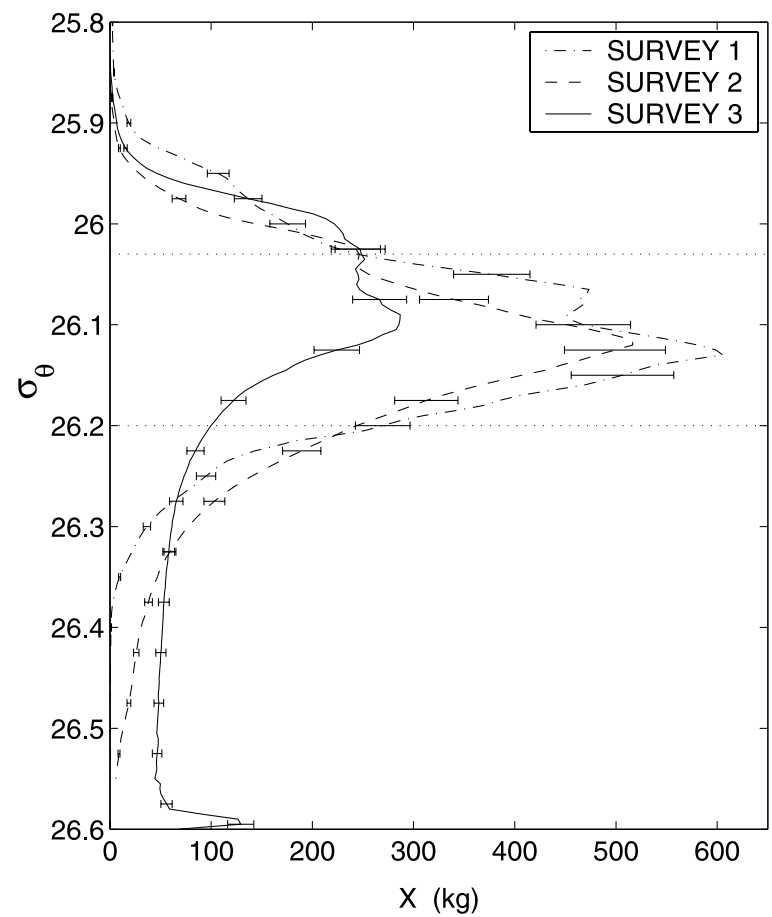

Figure 18. Experiment 5 diapycnal dye distribution. Plotted here are the inventories of dye as a function of $\sigma_{\theta}$ for the part of the patch deemed to be detached from the bottom. The dotted lines at $\sigma_{\theta}=26.03$ and 26.2 indicate the levels at which the diapycnal diffusivity was estimated (see text).

55-hour inset in Figure 15 was counted in this BBL and excluded from the inventory. The amount of dye involved was about $10 \%$ of the total. In Survey 3 all the dye north of the dashed line in the 106-hour inset in Figure 3 was in the BBL, and it represented about $31 \%$ of the total. It should be noted that the northern edge of the "off-bottom" dye was not delimited by this survey (106-hour inset in Figure 15). Since the plots in Figure 18 exclude the onshore components for Surveys 2 and 3, they show a loss of dye over time. Also, Figure 18 shows that dye moved into layers of greater density as time passed.

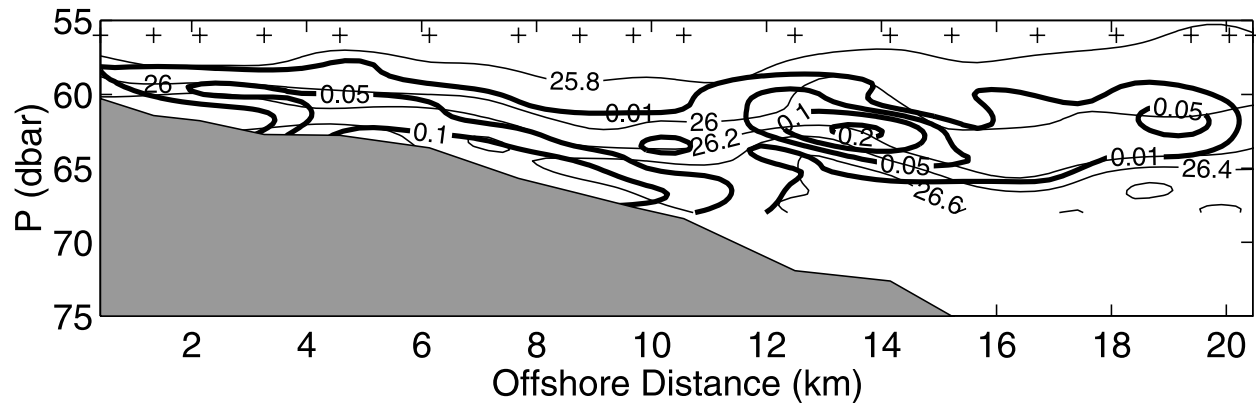

Figure 17. Cross-shelf dye distribution for Experiment 5, Survey 3, 107 hours after release. Vertical profiles of pressure and concentration from along-isobath sections have been averaged together on isopycnal surfaces to make this section. Concentration-weighted locations of the sections are indicated with crosses along the top axis. Thin lines are $\sigma_{\theta}$ contours; thick lines are dye contours, in $\mu \mathrm{g} / \mathrm{L}$. The detached part of the patch appears centered near $62 \mathrm{dbar}$, and $14 \mathrm{~km}$. The bottom-attached part of the patch can be seen as a secondary maximum at the bottom between 3 and $11 \mathrm{~km}$. 
[41] At $\sigma_{\theta}<26.03$ in Figure 18, however, there was relatively little change in the dye inventory. The amount of dye at these densities apparently decreased from $17 \mathrm{~kg}$ to $11 \mathrm{~kg}$ between Survey 1 and 2 and then increased to $16 \mathrm{~kg}$ by Survey 3 . These changes are within the uncertainty of the inventories. It is very unlikely that the amount of dye at these densities in the interior really decreased between Surveys 1 and 2, because the 26.03 isopycnal is high above the peak of the dye distribution and above the BBL. We conclude that the diffusion of dye through the $\sigma_{\theta}=26.03$ surface in the interior during the experiment was too small to be detected, and we estimate an upper limit for $K_{\text {dye }}$ at this level from the equation

$$
K_{\text {dye }}<\frac{-\Delta M}{\int \frac{\partial m}{\partial z} d t},
$$

where $\Delta M$ is the change in mass at $\sigma_{\theta}<26.03$ during the experiment and $m(z, t)$ is an integral of dye concentration at time $t$ on an isopycnal whose mean height is $z$, the integral being done over an area encompassing the interior part of the dye patch. We take $5 \mathrm{~kg}$ as an upper limit to $\Delta M$. We estimate the area-integrated vertical gradient $\partial m / \partial z$ graphically from the slopes of the curves in Figure 18 and the vertical density gradient, smoothing over the considerable structure in the profiles, using the following equation:

$$
\frac{\partial m}{\partial z}=\frac{\partial}{\partial \sigma_{\theta}}\left(X \frac{\partial \sigma_{\theta}}{\partial z}\right) \frac{\partial \sigma_{\theta}}{\partial z} .
$$

[42] This gradient is about $9 \mathrm{~kg} / \mathrm{m}^{2}$ for Surveys 1 and 2, but appears to be much smaller for Survey 3. As a lower bound for the time average, we take $6 \mathrm{~kg} / \mathrm{m}^{2}$. The time elapsed between Surveys 1 and 3 was 96 hours. The upper limit for $K_{\text {dye }}$ that results is $2.4 \times 10^{-6} \mathrm{~m}^{2} / \mathrm{s}$. The buoyancy frequency at $\sigma_{\theta}=26.03$ calculated from the mean density profiles was between 12 and $15 \mathrm{cph}$ for the various surveys. Hence this upper limit is very similar to the diffusivities for the upper part of the dye patch in Experiment $3\left(K_{\text {dye }}=1 \times\right.$ $\left.10^{-6} \mathrm{~m}^{2} / \mathrm{s} ; N=12 \mathrm{cph}\right)$ and for the whole dye patch in Experiment $4\left(K_{\text {dye }}=1.8 \times 10^{-6} \mathrm{~m}^{2} / \mathrm{s} ; N=16 \mathrm{cph}\right)$.

[43] Though there was undetectable flux of tracer upward through the $\sigma_{\theta}=26.03$ surface in the interior, there was clearly a downward flux of tracer below this surface. Figure 18 shows an increase in mass with time in the deep tail of the distribution, even though it leaves out much of the tracer in the bottom boundary layer in the onshore part of the patch. A rough estimate of the diffusivity at $\sigma_{\theta}=26.2$ can be made from a formula similar to that above, where now $\Delta M$ is the increase in mass inventory at $\sigma_{\theta}>26.2$, and $\partial \mathrm{m} / \partial z$ is estimated at $\sigma_{\theta}=26.2$. This gradient was about $40 \mathrm{~kg} / \mathrm{m}^{2}$ for Survey 1, and about $70 \mathrm{~kg} / \mathrm{m}^{2}$ for Surveys 2 and 3, the decreasing gradient in $X$ with time seen in Figure 18 being more than compensated by the increase in vertical density gradient seen in Figure 16 . The buoyancy frequency at $\sigma_{\theta}=26.2$ increased from $18 \mathrm{cph}$ in Survey 1 to $19 \mathrm{cph}$ in Survey 2, and then to $28 \mathrm{cph}$ in Survey 3. The increase in the amount of dye at $\sigma_{\theta}>26.2$ over the period of the experiment was approximately $19 \mathrm{~kg}$, including the dye in the BBL, on shore. As much as $22 \mathrm{~kg}$ more had crossed the $\sigma_{\theta}=26.2$ surface to get to the BBL and then crossed again to lighter densities as it moved on shore. Let us then

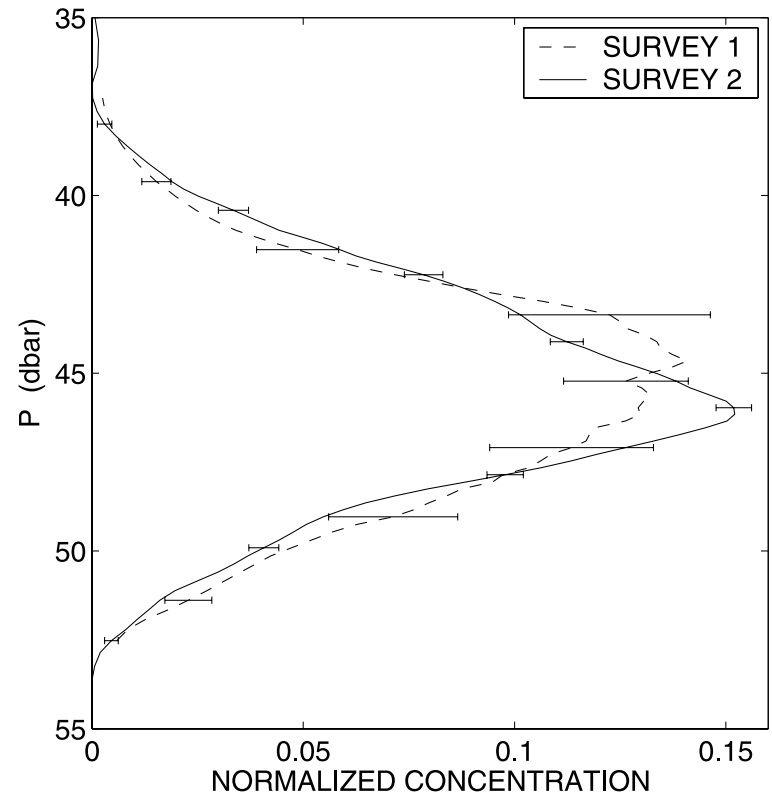

Figure 19. Mean dye profiles for Experiment 1. The mean $\mathrm{P}(\theta)$ curve for Survey 2 was used to convert the mean dye profiles into pressure coordinates. The change between the two profiles is immeasurable.

take $\Delta M=30 \pm 10 \mathrm{~kg}$. Using an average $\partial m / \partial z$ of $60 \pm$ $10 \mathrm{~kg} / \mathrm{m}^{2}$, we find $K_{\text {dye }}=1.4 \pm 0.7 \times 10^{-6} \mathrm{~m}^{2} / \mathrm{s}$ at $\sigma_{\theta}=$ 26.2. This estimate is for a region where the $\sigma_{\theta}=26.2$ surface lies 4 to $10 \mathrm{~m}$ above the bottom, underlain by a strongly stratified layer 1 to $2 \mathrm{~m}$ thick and then a more weakly stratified bottom boundary layer (Figure 16c).

\subsection{Experiment 1}

[44] A pilot experiment was performed near $41 \mathrm{~m}$ depth in September 1995 at the CMO site. The second of two surveys in this experiment was thorough, while the first survey was incomplete. There is no significant difference between the initial and final mean profiles, shown in Figure 19, though the initial profile is abnormally broad. Corrections for sensor lags and careful background corrections have not been made for this experiment, but doing so does not promise to change this conclusion. Beyond sensor lags, there are three possible explanations for the breadth of the initial profile. One is that the injection was not as well controlled as for the later experiments. The injection system was very similar to that used for the later experiments, except that the frame supporting the CTD and injection outlets was not isolated from the ship motion. Nevertheless, variation of density at the CTD during injection was no greater than in the later experiments. Another explanation is that we sampled only a part of the patch that had suffered an intense mixing event between injection and initial sampling. A third possibility is that such an intense mixing event affected the whole patch. In fact, a strong inertial wave created more shear than usual at the level of the dye between injection and initial sampling during this experiment. Richardson numbers were significantly lower during this survey than in any other survey examined from all the dye experiments, as can be seen from the first row in Table 3, which is discussed below. In any case, the diffu- 
Table 3. Shear and Stratification Statistics and Diffusivities

\begin{tabular}{|c|c|c|c|c|c|c|c|c|c|}
\hline Experiment & Survey & Depth, ${ }^{a} \mathrm{~m}$ & $n$ & $\begin{array}{c}\left\langle N^{2}\right\rangle, \\
10^{-4} \mathrm{~s}^{-2}\end{array}$ & $\begin{array}{c}\left\langle S^{2}\right\rangle, \\
10^{-4} \mathrm{~s}^{-2}\end{array}$ & $\left\langle S^{2} / N^{2}\right\rangle$ & Median $R i$ & $\begin{array}{c}K_{\mathrm{MG}}{ }^{\mathrm{b}} \\
10^{-6} \mathrm{~m}^{2} / \mathrm{s}\end{array}$ & $\begin{array}{c}K_{\text {dye }}, \\
10^{-6} \mathrm{~m}^{2} / \mathrm{s}\end{array}$ \\
\hline 1 & 1 & 43 & 274 & 7.5 & 6.3 & 1.05 & 1.2 & & \\
\hline 1 & 2 & 46 & 774 & 6.0 & 3.3 & 0.62 & 2.2 & 4 & $<15$ \\
\hline 3 & all & 46 & 769 & 3.9 & 1.8 & 0.45 & 3.5 & 3 & $1-9$ \\
\hline 4 & all & 17 & 1136 & 8.5 & 3.2 & 0.39 & 3.6 & 3 & $1.4-2.2$ \\
\hline $5^{\mathrm{c}}$ & 3 & 63 & 217 & 8.2 & 1.7 & 0.24 & 7.3 & 2 & $<2.4$ \\
\hline
\end{tabular}

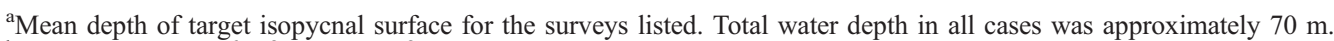

${ }^{\mathrm{b}} K_{\mathrm{MG}}=\left(5.2 \times 10^{-6} \mathrm{~m}^{2} / \mathrm{s}\right)\langle N S\rangle /\left\langle N^{2}\right\rangle$.

${ }^{\mathrm{c}}$ All data are for the upper part of the dye patch; $S$ could not be measured in the deeper layers.

sivity between the two surveys was undetectably small. If we take the initial condition as being similar in breadth to the other injections, then the final condition, which seems accurately measured in Survey 2, gives an upper limit to the diffusivity of $1.5 \times 10^{-5} \mathrm{~m}^{2} / \mathrm{s}$, at $N=13 \mathrm{cph}$.

\subsection{Experiment 2}

[45] Sundermeyer and Ledwell [2001] reported on lateral dispersion for Experiments 1 through 4, including Experiment 2, performed in September 1996. They used upper bounds for the diapycnal diffusivity of $(1.5,3,0.9$, and $0.4) \times 10^{-5} \mathrm{~m}^{2} / \mathrm{s}$ for Experiments 1 through 4, respectively. These upper bounds are consistent with the results reported here for Experiments 1, 3, and 4. We have not been able to make a very satisfactory estimate of $K_{\text {dye }}$ for Experiment 2 because of poor separation of the dye signal from background fluorescence in that experiment. Experiment 2 started just 4 days after the passing of Hurricane Edouard (Figure 2), which had reduced the buoyancy frequency to $6 \mathrm{cph}$ at the level of the dye release, a value considerably smaller than for the other experiments (Table 1). Hence $K_{\text {dye }}$ might be expected to be elevated for this experiment, both because of the smaller $N$ and because of energy lingering from the storm. The dissipation rates measured by OG04 imply a value of $K_{T}$ of approximately $1 \times 10^{-5} \mathrm{~m}^{2} / \mathrm{s}$ at the level of the release, well below the upper limit of $3 \times$ $10^{-5} \mathrm{~m}^{2} / \mathrm{s}$ reported by Sundermeyer and Ledwell [2001], but higher than for most of the other cases at higher $N$ considered here.

\section{Fine Structure Environment}

[46] The main source of energy for diapycnal mixing in the present experiments is presumably vertical shear in the horizontal velocities. It is important to characterize the shear and stratification at scales of meters along with any measurements of diapycnal diffusivity and dissipation in the stratified ocean so that experiments can be compared with one another and so that techniques for estimating diffusivities from relatively accessible fine-scale gradients can be developed. Progress has been made in relating dissipation rates to fine-scale shear and buoyancy frequency in the main pycnocline of the open ocean by Gregg [1989] and by Polzin et al. [1995], for example. MacKinnon and Gregg [2003] have developed a different formulation between the fine-scale gradients and dissipation rates at the CMO site, with which we will compare our results in section 5.2.

[47] Our ADCP observations indicate that fine-scale shear at the site is largely associated with internal tides, which are always present, and with inertial waves, which are often present. The shear can be amplified by the subtidal flow, and it can also be enhanced greatly, but briefly, by passing packets of solitary waves generated at the shelf edge and propagating shoreward [Sandstrom and Oakey, 1995; Colosi et al., 2001; MacKinnon and Gregg, 2003].

[48] Statistics of the shear and buoyancy frequency were calculated from the ADCP and tow-yo CTD data. Averaging periods of 2.5 min (Experiment 1) and 3 min (Experiments 3, 4, and 5) were used to reduce the root mean square noise in the ADCP velocities to a useful level of less than $1 \mathrm{~cm} / \mathrm{s}$. In these time intervals we typically obtained three or four CTD profiles in the swath sampled by the ADCP while the ship moved at 1 to $2 \mathrm{~m} / \mathrm{s}$. The ADCP bin size used in 1996 and 1997 with the broadband 300-kHz ADCP was $2 \mathrm{~m}$, while that used for Experiment 1 in 1995 with the narrowband $150-\mathrm{kHz}$ ADCP was $4 \mathrm{~m}$. The beam angle for the ADCPs is $20^{\circ}$. Hence the resolution of the shear measurements is on the order of $8 \mathrm{~m}$ vertically, by $200 \mathrm{~m}$ in the along-track direction, by a few tens of meters in the across-track direction.

[49] We have calculated the square of the magnitude of the vertical shear vector $S^{2}$ by taking differences of the ADCP velocities in adjacent bins for the 4-m binned narrowband data, and skipping a bin in the middle for the 2-m binned broadband data. A triangle filter with base twice the bin size is applied to the raw ADCP data to obtain the velocities that enter these shears. As a result, skipping the middle bin for the 2-m data results in almost the same filter as taking the difference of adjacent 4-m bins, and we have not made further adjustments. The same filter is applied to the CTD data to obtain $N^{2}$. Some statistics for $S^{2}$ and $N^{2}$ are listed in Table 3 by experiment and survey.

[50] The median gradient Richardson number, $R i$, measured at the resolution described above, is also listed in Table 3 . It was generally greater than 1 , while the frequency of occurrence of $R i<1 / 4$ was typically just a few percent, and these occurrences could easily be due to noise. The flow might well be unstable more frequently at smaller time and space scales than we were able to resolve. We present these data on $R i$ for comparison with other experiments.

\section{Comparison With Dissipation-Based Estimates}

\subsection{EPSONDE Measurements}

[51] Profiles of temperature and velocity microstructure were measured during the dye experiments on the days between dye surveys by OG04 with their lightly tethered EPSONDE profiler. Their methods and results are described in detail in the companion paper (OG04). They participated in Experiments 2 through 5, but were not present for 
Table 4. Comparison of $K_{\text {dye }}$ With $K_{T}$ From OG04

\begin{tabular}{cccccc}
\hline Experiment & $\sigma_{\theta}$ & Depth, m & $N,{ }^{\mathrm{a}} \mathrm{cph}$ & $K_{\text {dye }}, 10^{-6} \mathrm{~m}^{2} / \mathrm{s}$ & $K_{T}{ }^{\mathrm{b}} 10^{-6} \mathrm{~m}^{2} / \mathrm{s}$ \\
\hline 3 & $24.25-24.32$ & $43-45$ & $9-10$ & $1-3$ & $1.2-2.2$ \\
3 & $24.35-24.50$ & $47-49$ & $7-12$ & $4-9$ & $1.4-2.2$ \\
4 & $24.25-24.75$ & $12-18$ & $15-17$ & $1.4-2.2$ & $1.0-2.0$ \\
5 & 26.05 & $63-66$ & $12-15$ & $<2.4$ & $2.0-2.8$ \\
5 & 26.2 & $64-68$ & $18-28$ & $0.7-2.1$ & $1.9-3.3$ \\
\hline
\end{tabular}

${ }^{\text {a}}$ The range in $N$ indicates temporal and vertical variations in the isopycnally averaged density profiles for the various surveys over the depth range in question.

${ }^{\mathrm{b}} K_{T}$ values are from OG04.

Experiment 1, the pilot experiment in 1995. In general, they found a diffusivity for heat $K_{T}$ in the range of $10^{-6}$ to $10^{-5} \mathrm{~m}^{2} / \mathrm{s}$ at the level of the dye patches, in agreement with the dye measurements. In most cases the agreement between the two methods was very close, the only significant difference occurring for the deep part of Experiment 3. The comparisons between $K_{\text {dye }}$ and $K_{T}$ are summarized in Table 4.

[52] We did not succeed in Experiment 2 in measuring $K_{\text {dye }}$. OG04 did succeed, however, in determining a value for $K_{T}$ of approximately $10^{-5} \mathrm{~m}^{2} / \mathrm{s}$ at the level of the dye release. The buoyancy frequency $N$ was about $6 \mathrm{cph}$ in this case, i.e., about half as great as for the other experiments, and $K_{T}$ was higher than in the other experiments.

[53] In Experiment 3, $K_{\text {dye }}$ averaged over the 4 days of the experiment was around $10^{-6} \mathrm{~m}^{2} / \mathrm{s}$ in the few meters above the target density surface, but increased to around $10^{-5} \mathrm{~m}^{2} / \mathrm{s}$ in the few meters below the target density surface. The mixing was not uniform with time: Most of the mixing below the target surface occurred between the second and third dye survey. The microstructure results, averaged over all the measurements, do not show such a strong depth dependence for $K_{T}$. Rather, they give an average value of approximately $1.7 \times 10^{-6} \mathrm{~m}^{2} / \mathrm{s}$ at all levels occupied by the dye. If anything, $K_{T}$ decreased slightly with increasing depth.

[54] We speculate that this difference arose from temporal intermittency of mixing events, although the evidence is scanty. Figure 20 shows the shear at 2-m resolution from the shipboard ADCP for the duration of Experiment 3. An area of high shear appears below $50 \mathrm{~m}$ depth between Survey 2 and Survey 3, around day 259.3. A detail of this event is shown in Figure 21, with the isopycnal surfaces at $\sigma_{\theta}=$ 24.35 and 24.55 overlaid on the shear plot. These two isopycnals delimit the broadly mixed lower part of the dye patch found in Survey 3 (Figure 7). A downward displacement brought this isopycnal layer into the high shear region at day 259.35, as revealed by the SeaBird CTD cast performed at the start of a line of EPSONDE microstructure profiles. The gradient Richardson number was about unity in this $2-\mathrm{m} \times 3$-min bin. The first two of the EPSONDE profiles, taken about 17 and 21 min after the CTD cast, show elevated dissipation rates $\left(10^{-8}\right.$ to $10^{-7} \mathrm{~W} / \mathrm{kg}$ ) between 50 and $60 \mathrm{dbar}$, but these were included in the averages of OG04. We do not know how long the dye patch was subject to high shear during this event, how widespread the event was, or how intense the mixing. It seems possible to us that one or two such events, unluckily missed by the microstructure profiling, might have caused the relatively large mixing of the dye patch seen in the deep part of Experiment 3.

[55] Experiment 4 was the most straightforward for the dye, in spite of the solar heating. It gave $K_{\text {dye }}=1.8 \pm$ $0.4 \times 10^{-6} \mathrm{~m}^{2} / \mathrm{s}$, with no obvious depth dependence. The EPSONDE measurements gave $K_{T}=1.5 \pm 0.5 \times$ $10^{-6} \mathrm{~m}^{2} / \mathrm{s}$. Although $K_{T}$ increased with depth in general,
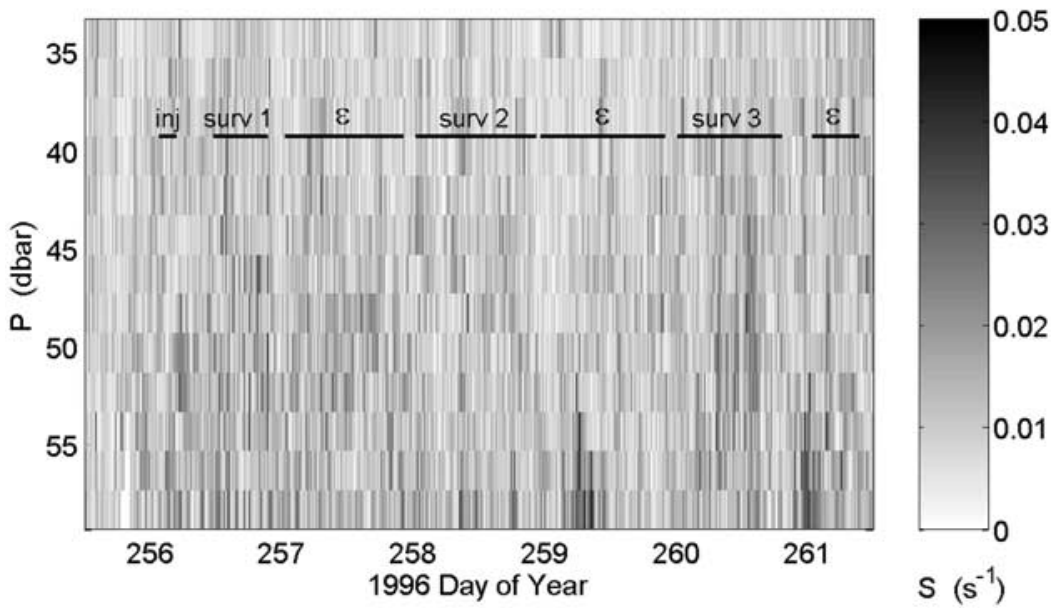

Figure 20. Shear during Experiment 3. $S$ is the magnitude of the shear vector calculated from the difference between 3 -min $\times 2-\mathrm{m} \mathrm{ADCP}$ velocities. The phases of the experiment indicated are: inj, injection; surv 1, 2, 3, dye surveys; $\varepsilon$, EPSONDE surveys. A detail of the high shear event near 259.3 below 53 dbar is shown in Figure 21. 


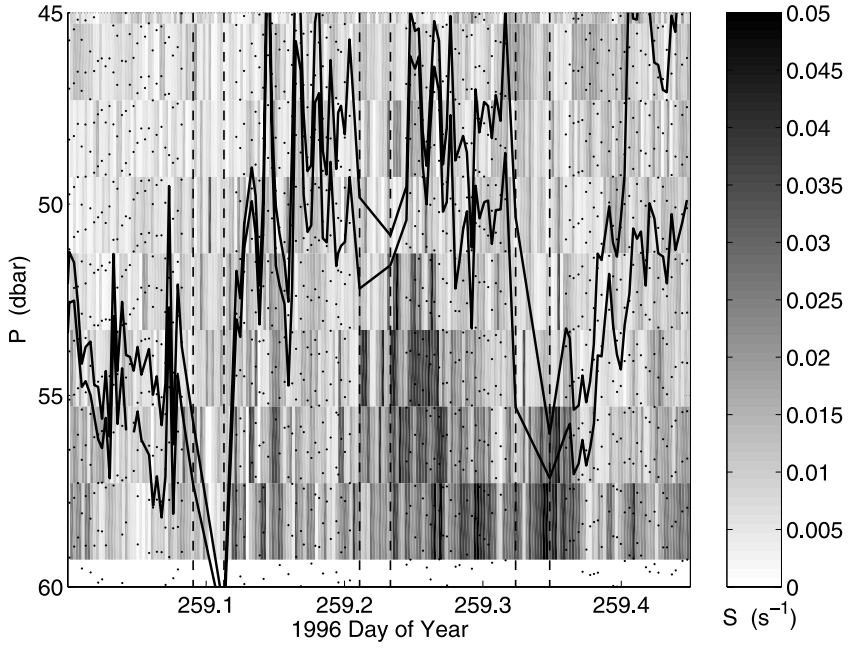

Figure 21. High shear event during Experiment 3. The gray scale shear is a detail from Figure 20. The dots show the locations of CTD measurements from the EPSONDE profiler; the vertical dashed lines indicate where SeaBird CTD measurements were made. The upper and lower solid curves indicate the 24.35 and 24.55 potential density levels estimated from these data. This density layer dips into the region of high shear at day 259.35, just before the start of an EPSONDE station.

there was no strong trend with depth within the dye layer. Hence, in this experiment the agreement between $K_{\text {dye }}$ and $K_{T}$ was quite close.

[56] In Experiment 5 we found an upper limit for $K_{\text {dye }}$ of $2.4 \times 10^{-6} \mathrm{~m}^{2} / \mathrm{s}$ above the target surface, at $\sigma_{\theta}=26.03 . K_{T}$ at this level was found to be $2.4 \pm 0.4 \times 10^{-6} \mathrm{~m}^{2} / \mathrm{s}$ by OG04, favoring the upper limit from the dye analysis. We estimated a value for $K_{\text {dye }}$ at $\sigma_{\theta}=26.2$, below the target surface, of $1.4 \pm 0.7 \times 10^{-6} \mathrm{~m}^{2} / \mathrm{s} . K_{T}$ reported by OG04 below the target density surface was (1.9 to 3.3$) \times$ $10^{-6} \mathrm{~m}^{2} / \mathrm{s}$. The two uncertainty ranges barely overlap, so it is likely that there is a difference due to temporal or spatial variability.

[57] Shear measurements from the ADCP are not available in the deep part of Experiment 5 because bottom reflections from beam sidelobes obscure the deep data. However, the 8-m bottom tripod described by Shaw et al. [2001] had been redeployed at the CMO site in support of our 1997 experiments. Data from acoustic velocimeters and temperature probes on this tripod show a few events of high shear and low gradient Richardson number in the layer of strong stratification in the deep part of the dye patch. As luck would have it, these high shear events all occurred during EPSONDE sampling, and so offer a reasonable explanation for the elevated value of $K_{T}$ relative to $K_{\text {dye }}$.

[58] Although the temperature and salinity gradients across the layer of strong stratification deep in Experiment 5 were conducive to double-diffusive convection, there were no signs that this process played a role in the mixing. Neither sharp steps in the hydrographic profiles nor elevated temperature variance dissipation rates were observed.

[59] In summary, estimates of $K_{\text {dye }}$ from the dye experiments and $K_{T}$ from dissipation measurements agree quite closely with one another in all but one case, the deep part of Experiment 3. It is important to note, in making this comparison, that there are at least 50 hours of microstructure profiling for each experiment, which means that all phases of the tide and various internal wave conditions are sampled. We also argue that the dye surveys were sufficiently thorough to delimit the dye patch and to obtain mean vertical profiles representative of the patch.

\subsection{MacKinnon and Gregg Measurements}

[60] MacKinnon and Gregg [2003] estimated the diffusivity of density $K_{\rho}$ from microstructure profiles obtained at the CMO site in August 1996. Their cruise was the month before the cruise on which we did Experiments 2 and 3, but the stratification was greatly weakened near the end of their cruise by the passage of Hurricane Edouard. The values for $K_{\rho}$ that they found were only slightly greater than we have found, namely (5 to 20$) \times 10^{-6} \mathrm{~m}^{2} / \mathrm{s}$. Furthermore, we can use a scaling formula developed by MacKinnon and Gregg [2003] to make a more direct comparison between our measurements and theirs.

[61] MacKinnon and Gregg [2003] measured the dissipation rate of turbulent kinetic energy $\varepsilon$ with a shear probe, the stratification with a CTD, and the shear with the shipboard ADCP, and found that for data sets from which solibore events were excluded, $\varepsilon$ scales with the product of $N$ and $S$ as follows:

$$
\varepsilon_{\mathrm{MG}}=\frac{\varepsilon_{0}}{N_{0}^{2}} S N
$$

where $\varepsilon_{0}=1.8 \times 10^{-11} \mathrm{~W} / \mathrm{kg}$ and $N_{0}=8.4 \times 10^{-4} \mathrm{~s}^{-1}$, and where $N$ and $S$ are measured with the filter described in section 4 for 4-m bin data. When solibores were present the dissipation was greater than given by this scaling. If the Osborn [1980] relation for the diffusivity of density is used,

$$
K=\Gamma \frac{\langle\varepsilon\rangle}{\left\langle N^{2}\right\rangle},
$$

then the estimate for the diffusivity based on the MacKinnon and Gregg scaling is

$$
K_{\mathrm{MG}}=\Gamma \frac{\varepsilon_{0}}{N_{0}^{2}} \frac{\langle S N\rangle}{\left\langle N^{2}\right\rangle}
$$

where the brackets indicate an average over a large number of measurements, and where $\Gamma$ is a dimensionless number approximately equal to 0.2 (see OG04 for a study of $\Gamma$ in the present experiment). Estimates of $K_{\mathrm{MG}}$ from equation (12) have been made from our ADCP and CTD data, and they are quite consistent with the diffusivities inferred from the dye dispersion (Table 3). The range of $K_{\mathrm{MG}}$ in our various experiments is too limited to provide an independent test of the scaling suggested by MacKinnon and Gregg. What can be said is that the two cruises found similar diffusivities and similar values for $\langle S N\rangle /\left\langle N^{2}\right\rangle$. Although the effect of the passage of solitary wave packets cannot be removed from the dye dispersion, while they were removed from the analysis of MacKinnon and Gregg, OG04 have shown that baroclinic energy was always much less during our experiments than during the solibore events seen by MacKinnon and Gregg 
[2003]. Hence our comparison with their results without solibores seems reasonable.

\subsection{Towed Conductivity Results}

[62] Rehmann and Duda [2000] obtained several hours of microconductivity data from the sampling vehicle while it was towed at nearly constant depth in the lower $10 \mathrm{~m}$ of the water column during Experiment 5. They found a minimum for $K_{T}$ of approximately $1 \times 10^{-6} \mathrm{~m}^{2} / \mathrm{s}$ near $\sigma_{\theta}=26.2$, where the value of $K_{\text {dye }}$ estimated in section 3.3 was $1.4 \pm$ $0.7 \times 10^{-6} \mathrm{~m}^{2} / \mathrm{s}$. They found that $K_{T}$ increased to around $6 \times 10^{-6} \mathrm{~m}^{2} / \mathrm{s}$ while still within the layer of strong stratification seen between $\sigma_{\theta}=26.1$ and 26.4 (Figure 16), and then increased dramatically to nearly $10^{-3} \mathrm{~m}^{2} / \mathrm{s}$ in the layer of weak stratification at values of $\sigma_{\theta}>26.5$, which seemed to be a mixed bottom boundary layer [see Rehmann and Duda, 2000]. In the upper part of the dye patch, where the stratification diminishes with height, $K_{T}$ from the towed conductivity sensor increased from $1 \times 10^{-6} \mathrm{~m}^{2} / \mathrm{s}$ at $\sigma_{\theta}=$ 26.1 to a maximum of $1 \times 10^{-5} \mathrm{~m}^{2} / \mathrm{s}$ near $\sigma_{\theta}=26.03$, which is where an upper limit of $2.4 \times 10^{-6} \mathrm{~m}^{2} / \mathrm{s}$ was estimated for $K_{\text {dye }}$ in section 3.3. In this case the estimate from towed microstructure is several times higher than that from the dye.

[63] Perhaps this difference is due to the shifting of the region of more intense mixing from one time to another, as suggested, for example, by the dye results from Experiment 3. It is also true that the amount of time the towed system was able to measure dissipation at any level was less than an hour, and therefore one cannot expect close agreement with the 96-hour average from the dye. The dye and towed microstructure results do agree, however, that the diffusivity is on the order of $10^{-6}$ to $10^{-5} \mathrm{~m}^{2} / \mathrm{s}$ in the bottom $10 \mathrm{~m}$ in Experiment 5.

[64] Rehmann and Duda [2000] also reported measurements from a 39-km-long cross-isobath tow-yo that covered nearly the whole water column after Experiment 5 was finished, and passed though the sites of Experiments 4 and 5. Duda and Rehmann [2002] re-analyzed the results, selecting only the data from regions stable to double diffusion, and that analysis is more pertinent to the present discussion. Averaging temperature variance dissipation rate $\chi$ and vertical temperature gradient in bins defined by buoyancy frequency, they found that the thermal diffusivity $K_{T}$ estimated from the Osborn-Cox relation would be approximately $1.5 \times 10^{-5} \mathrm{~m}^{2} / \mathrm{s}$ at $N=16 \mathrm{cph}$, and varies with $N^{-2.5}$. Experiment 4 reported here gave a value of a little under $2 \times 10^{-6} \mathrm{~m}^{2} / \mathrm{s}$ at this buoyancy frequency in the upper thermocline a week earlier. Comparison of the two results is perhaps not fair for several reasons, beyond the limited averaging time for the towed microstructure measurements. One is that the method of averaging chosen by Duda and Rehmann [2002] explores the variation of buoyancy flux within the stratification fine structure, and is not focused on any particular depth or isopycnal surface, as the dye is. Another factor is the mismatch of a week in the time of the measurements. A third factor is that although the microstructure tow-yo passed through the site of the dye experiments, it also went into shallower water where solitary waves appeared to be dissipating more energy. Finally, it is possible for layers of low mixing to block the diffusion of dye for times that are of the same order as the time between significant mixing events, while the towed sensor is not inhibited by such temporary barriers [see, e.g., Duda and Rehmann, 2002].

\section{Discussion}

[65] The experiments have shown that the diapycnal diffusivities at the site of the Coastal Mixing and Optics Experiment in summertime conditions are generally $10^{-6}$ to $10^{-5} \mathrm{~m}^{2} / \mathrm{s}$ throughout the stratified region. We have speculated that the higher end of this range was approached when short-lived high-shear events occurred during the 4 days of an experiment, as in the lower part of the dye patch in Experiment 3, and in the initial stage of Experiment 1. This speculation is reminiscent of the conclusion of MacKinnon and Gregg [2003], who found that half of the dissipation in the summer pycnocline over 14 days of observations occurred during the passage of four solitary wave packets. These wave packets take about an hour to pass a fixed point, and though they have the potential to occur with each semidiurnal tide, their strength varies greatly. OG04 show that the total baroclinic energy during Experiment 3 was much weaker than for the period of MacKinnon and Gregg's measurements, probably due to the weakening of the stratification brought on by Hurricane Edouard. Hence, strong solitary wave packets seemed to be absent during Experiment 3. Still, shear events of some kind, too localized in the deep layer of stratification to register in the baroclinic shear energy for the whole water column, may have been responsible for mixing the deep dye in this experiment. Similarly, shear associated with inertial waves may have mixed the dye in Experiment 1 between the injection and initial sampling.

[66] We do not know whether the diffusivities we have measured are typical of the continental shelf. One avenue for comparison is through the ambient shear levels or the gradient $R i$, though more must be known about how these variables, measured at scales of several meters, are related to energy cascade to the smaller scales of mixing events. The relation found between dissipation and shear by Gregg [1989] and Polzin et al. [1995] was for data from the open ocean where the shape of the internal wave spectrum is similar to the empirical spectrum of Garrett and Munk (GM) [see, e.g., Munk, 1981]. The wave spectrum on the shelf is quite different from GM, and in fact, MacKinnon and Gregg [2003] found that the dissipation did not scale with the shear according to the relation of Gregg [1989] but did scale according to the relation discussed in section 5.2. More study of the relation between diffusivities and shear and stratification at fine scales is certainly warranted.

[67] One might have expected the diffusivities to be much greater at the CMO site than in the open ocean due to the large tidal currents, and the proximity of the boundaries. Diffusivities estimated by Gregg [1989] and Polzin et al. [1995] from the relation mentioned above for the open ocean are approximately $6 \times 10^{-6} \mathrm{~m}^{2} / \mathrm{s}$, independent of $N$, in the background GM internal wave field at midlatitudes, and in the absence of double diffusion. This value is uncannily similar to the diffusivities we have found at the CMO site. The fine-scale shear was not greater at the CMO site than it is in the GM spectrum. The ratio of the mean square shear, estimated as described in section 4 from the 
ADCP measurements, to the square of the mean value of $N$ was 0.6, 0.4, and 0.3 for Experiment 3, Experiment 4, and the upper part of Experiment 5, respectively. These values are all less than the value of 0.7 that results for the GM shear spectrum when integrated to wave numbers of $0.1 \mathrm{cpm}$ [e.g., Polzin et al., 1995]. By this measure, it perhaps is not surprising that the diffusivities at the CMO site are no larger than in the open ocean.

[68] The diffusivities we have found are quite small, in some important ways. For example, a heat, salt, or nutrient anomaly with a depth scale of $10 \mathrm{~m}$ would take on the order of 4 months to be dissipated by diapycnal mixing with a diffusivity of $10^{-5} \mathrm{~m}^{2} / \mathrm{s}$. The flow along Mid-Atlantic Bight would carry a fluid particle $1000 \mathrm{~km}$ in this time, from the CMO site to Cape Hatteras, where it is likely to leave the shelf.

[69] Over 4 months, however, a patch of water might be subjected to one or more storms which could dominate the diapycnal mixing for the season. Summer storms with wind stress magnitudes of $1 \mathrm{~Pa}$ seem able to drive much greater diffusivities than we measured, as evidenced by the destratification of the water column by Hurricane Edouard [Lentz et al., 2003]. On the other hand, more common wind events with stress magnitudes on the order of $0.2 \mathrm{~Pa}$ were unable to raise the diffusivity above $10^{-5} \mathrm{~m}^{2} / \mathrm{s}$ at the CMO site.

[70] The dye experiments measure diffusivity of a passive tracer, but they do not tell us the vertical viscosity. Momentum transfer may have contributions from internal wave interactions as well as from turbulence. OG04 have estimated eddy viscosities from their data and the ADCP shear, and find that the turbulent Prandtl number increased from 5 to 20 as $R i$ increased from 1 to 4.5 .

\section{Conclusion}

[71] The evidence from both our dye experiments and the microstructure measurements of Oakey and Greenan [2004] is that the diffusivity at the study site was typically $10^{-6}$ to $10^{-5} \mathrm{~m}^{2} / \mathrm{s}$ in conditions of summer and fall stratification. The two methods agree on this point, and in all but one case give estimates which are remarkably close to one another for a given layer and time period. There are hints from the experiments that much of even this small amount of mixing occurs during high shear events lasting an hour or so and occurring with a frequency of less than once per day. Such intermittency makes comparison between dye and dissipation measurements demanding. The likelihood of domination of the mixing by special events adds to the challenge of measuring diapycnal mixing, as well as to the challenge of parameterizing mixing in models of shelf circulation and ecology.

\section{Appendix A: Sensor Lag Corrections}

[72] It was necessary to account for time lags between the conductivity cell and the temperature sensor and between the dye sensing volume and the CTD sensors. It is well known that salinity errors can be reduced by using a filtered version of the temperature to calculate salinity with the SeaBird 911plus system [Lueck, 1990; Lueck and Picklo, 1990], to account for the lag of the conductivity cell wall temperature relative to the temperature of the bulk of the
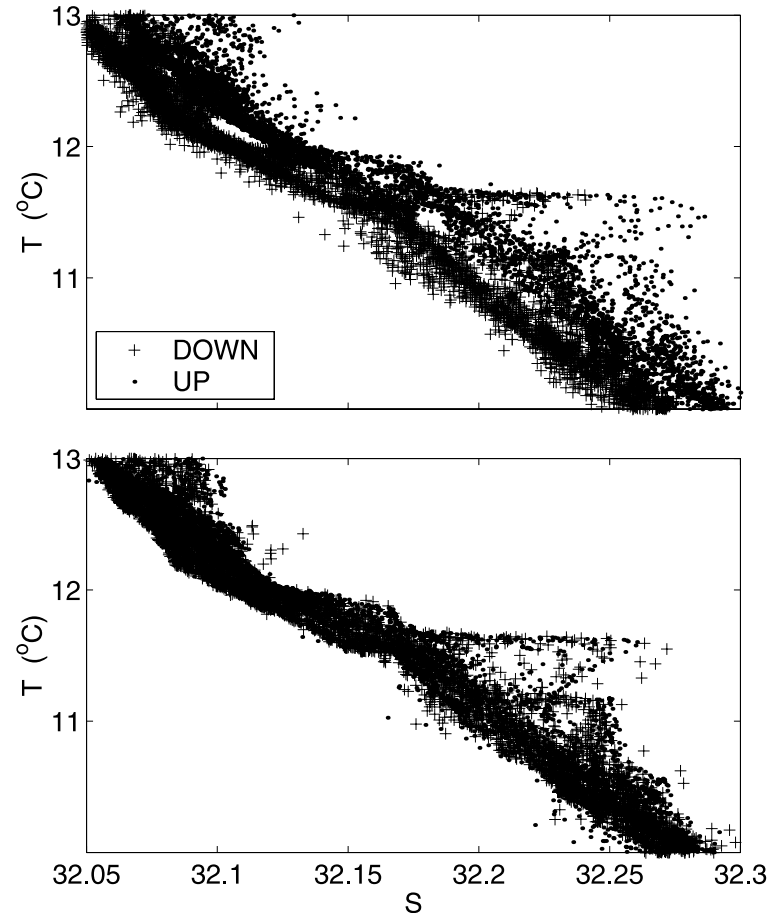

Figure A1. Effect on $\mathrm{T} / \mathrm{S}$ scatterplots of applying a temperature lag for a transect in Survey 3 of Experiment 3. The top panel has only the Lueck and Picklo [1990] correction applied, and the gap that appears in the midst of the points essentially separates up from down data. In the bottom panel the temperature used in the salinity calculation has been advanced by $0.1 \mathrm{~s}$, chosen to minimize the difference between the mean up and down T/S plots.

water in the cell. This filtering was done in real time throughout the cruises. The constants that seemed to work fairly well were 0.023 for the fraction of the cell volume occupied by the boundary layer and $10 \mathrm{~s}$ for the thermal time constant of the cell walls, as judged by visual inspection of the data early in each cruise. However, comparison of the mean of groups of upcasts with the mean of the intervening downcasts in the tow-yos revealed that the correction could be improved upon (Figure A1, top panel).

[73] Rather than rerun the Lueck-Picklo algorithm on the original binary data, we corrected the data, as already processed with this algorithm, by offsetting the time of the temperature record used for the salinity calculation. This seemed to work at least as well as adjusting the constants in the Lueck-Picklo algorithm. The optimum offset was found for each data file by adjusting it until the mean salinity over a range of temperatures for the upcasts was the same as the mean salinity for the downcasts. Averaging was done over the full set of profiles from the file and over a temperature range that was sampled in most of the profiles. The files for which this procedure was applied were 40 to $60 \mathrm{~min}$ long, and comprised around 50 profiles each. The lag was allowed to vary with file to allow for changes in the characteristics of the pumped $\mathrm{C} / \mathrm{T}$ pair, such as cleanliness and flow rate. The lags applied were always less than $1 \mathrm{~s}$, usually much less. The bottom panel of Figure A1 shows the improvement obtained for one of the files with a lag of 
$-0.1 \mathrm{~s}$ applied. The negative value of the lag implies that the Lueck-Picklo correction used was too strong.

[74] The dye data also suffer from various lags. The first, and most straightforward is due to an $\mathrm{R} / \mathrm{C}$ filter within the Chelsea Instruments fluorometer itself. Though the fluorometer flashes and samples at $5.5 \mathrm{~Hz}$, this $\mathrm{R} / \mathrm{C}$ filter has a 1 -s time constant. It is applied to the signal before a logarithmic amplifier is applied. To reverse the effect of this filter mathematically, we first take the antilogarithm of the dye signal and then use the formula

$$
x(t)=y(t)+\tau(d y / d t),
$$

where $y$ is the antilog of the original signal, $t$ is the time, $\tau$ is the time constant of the $\mathrm{R} / \mathrm{C}$ filter, and $x$ is the recovered signal. This formula is discretized with a centered difference approximation for the derivative applied to the $6-\mathrm{Hz}$ data produced by the CTD system. The noise added by the differentiation is worth the improvement in spatial resolution of the measurements. Poor spatial resolution converts to very poor resolution in density in strong density gradients. An example of the improvement obtained with this inversion is shown in Figure A2.

[75] A systematic difference between up and down dye profiles as a function of potential density usually remains after inversion of the $\mathrm{R} / \mathrm{C}$ filter just discussed. This difference can arise from systematic errors in salinity of the sort considered above, or from a relative delay in the water reaching the dye sensing volume, or from both. Correction to the dye data was made in a series of steps for each crossing of the dye patch. The first step was to adjust the time lag for the temperature used in the salinity calculation for the crossing. This was done exactly as explained above, but for a more restricted data set: just the profiles and temperature range within which the dye concentration was above background. Slightly different lags were obtained from this procedure than for the whole file containing the dye crossing. An example of the effect of making this correction on the dye profiles is shown in Figures $\mathrm{A} 2 \mathrm{~b}$ and A2c. While some of the profiles are sharpened, the match between up and down profiles is made worse in some cases. This is fixed when the lags are applied to the fluorometer signal as described below. Because we know from the $\mathrm{T} / \mathrm{S}$ plots that the temperature lags improve the salinity data significantly, the implication is that the uncorrected fluorometer lag was fortuitously compensating for the uncorrected CTD lags.

[76] Having made the correction to the salinity, and hence the density, we found lags for the fluorometer signal relative to the $\mathrm{C} / \mathrm{T}$ sensors that would minimize the difference in shape and location between the up and down concentration profiles. We surmise that this correction is needed because of a delay in the arrival of ambient water at the fluorometer relative to arrival at the CTD sensors. The fluorometer sensing volume is open and depends on flow past it. It was displaced about $20 \mathrm{~cm}$ to the side of the $\mathrm{C} / \mathrm{T}$ pairs, which were pumped. The delay may well depend on the speed of the sampling sled through the water, and may vary considerably even during a single profile due to fluctuations in the flow past the sled. It was impossible to account for every fluctuation. Rather, we sought two lags for each transect through the dye, comprising a number of profiles,
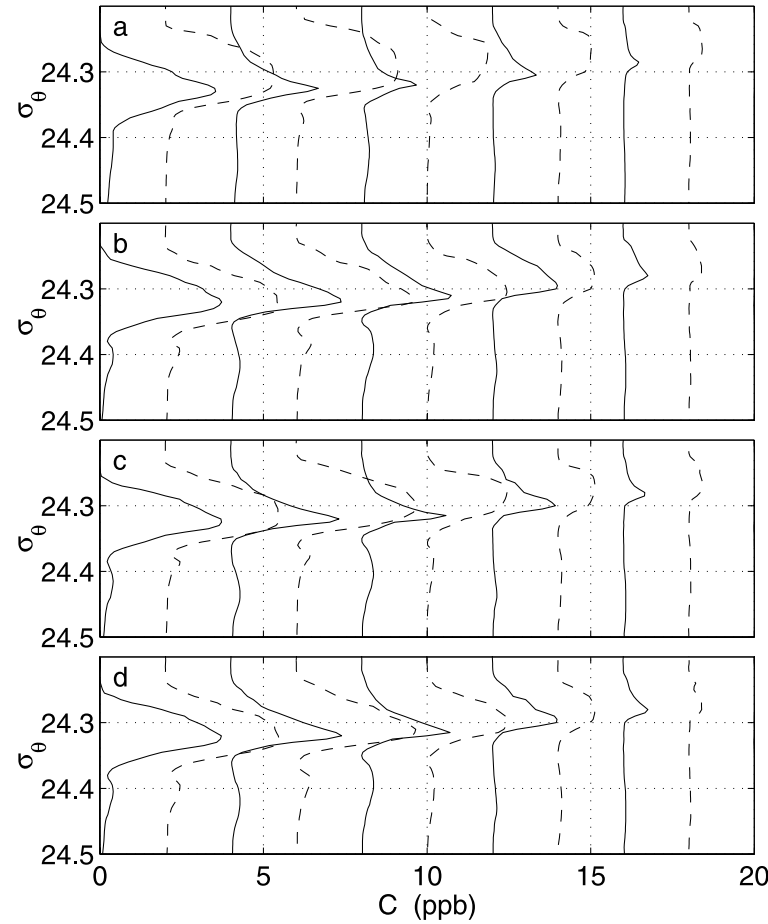

Figure A2. Effect of various corrections on a sequence of dye profiles from Survey 3 of Experiment 3. Each panel shows the same series of concentration profiles as a function of $\sigma_{\theta}$, with successive profiles displaced by $2 \mu \mathrm{g} / \mathrm{L}$ from the previous profile. Down profiles (solid) alternate with up profiles (dashed). (a) No corrections have been made. (b) The $\mathrm{R} / \mathrm{C}$ filter in the fluorometer has been undone, sharpening the peaks. (c) In addition, temperature has been advanced by $0.11 \mathrm{~s}$ relative to conductivity before calculating salinity and $\sigma_{\theta}$, making minor improvements as well as doing some damage. (d) In addition, concentration has been advanced by $0.16 \mathrm{~s}$ for the downcasts and by $0.33 \mathrm{~s}$ for the upcasts, undoing most of the damage done in going from Figure $\mathrm{A} 2 \mathrm{~b}$ to Figure $\mathrm{A} 2 \mathrm{c}$ and keeping most of the improvement.

one for the upcasts and the other for the downcasts. Discrimination between up and down lags seemed sensible, since the speed of the sled through the water was much greater when hauling in than when paying out. The optimization was performed by visual inspection of the set of profiles in density space, statistical procedures having been found difficult to apply because of variations in shape and in level of dye concentration within a transect. Figures A2c and $\mathrm{A} 2 \mathrm{~d}$ show the effect of applying this correction to the concentration data, in addition to the corrections discussed already. There are still differences between up and down profiles that appear to be artifacts, but the improvement over Figures A2a and A2c is considerable.

[77] Acknowledgments. We are grateful to the captain and crew of $\mathrm{R} / \mathrm{V}$ Oceanus, and the Marine Department at WHOI for their excellent support for the field work. A. Williams, J. Trowbridge, and W. Shaw shared with us the data from their tripod for Experiment 5, and T. Boyd and M. Levine shared data from an internal wave mooring for Experiment 3. Cynthia Sellers helped organize and reduce the data. She, Terence Donoghue, Stewart Sutherland, Kenneth Prada, Sean Kery, Chris Rehmann, Brian Guest, Craig Marquette, Brian Connolly, David Ciochetto, Wayne Spencer, and 
Scott Madin assisted with the preparations and execution of the field work. Neil Oakey and Blair Greenan have been close collaborators in this work Jennifer MacKinnon and Michael Gregg have been generous in sharing ideas and early drafts of their papers. This work was part of the ONR Coastal Mixing and Optics Experiment, and was funded by grants N00014-95-1 0633, N00014-95-1-1063, N00014-95-1-1064, and N00014-01-1-0211 Completion of this paper was supported by the Edward W. and Ellyn B. Scripps Chair awarded to J. Ledwell. H. Seim's participation was supported by ONR grant N00014-96-1-0616. Woods Hole Oceanographic Institution contribution 11243

\section{References}

Bretherton, F. P., R. E. Davis, and C. B. Fandry (1976), A technique for objective analysis and design of oceanographic experiments applied to MODE-73, Deep Sea Res., 23, 559-582.

Colosi, J. A., R. C. Beardsley, J. F. Lynch, G. Gawarkiewicz, C. S. Chiu, and A. Scotti (2001), Observations of nonlinear internal waves on the outer New England continental shelf during the summer Shelfbreak Primer study, J. Geophys. Res., 106(C5), 9587-9601.

Dickey, T. D., and A. J. Williams III (2001), Interdisciplinary ocean process studies on the New England Shelf, J. Geophys. Res., 106(C5), $9427-$ 9434.

Duda, T., and C. Rehmann (2002), Systematic microstructure variability in double-diffusively stable coastal waters of nonuniform density gradient, J. Geophys. Res., 107(C10), 3144, doi:10.1029/2001JC000844.

Gregg, M. C. (1989), Scaling turbulent dissipation in the thermocline, J. Geophys. Res., 94(C7), 9686-9698.

Horne, E. P. W., J. W. Loder, C. E. Namie, and N. S. Oakey (1996), Turbulence dissipation rates and nitrate supply in the upper water column on Georges Bank, Deep Sea Res., 43, 1683-1712.

Houghton, R. W. (1997), Lagrangian flow at the foot of a shelfbreak front using a dye tracer injected into the bottom boundary layer, Geophys. Res. Lett., 24, 2035-2038.

Houghton, R. (2002), Diapycnal flow through a tidal front: A dye tracer study on Georges Bank, J. Mar. Sci., 37, 31-46.

Houghton, R. W., and C. Ho. (2001), Diapycnal flow through the Georges Bank tidal front: A dye tracer study, Geophys. Res. Lett., 28, 33-36.

Houghton, R., and M. Visbeck (1998), Upwelling and convergence in the Middle Atlantic Bight, Geophys. Res. Lett., 25, 2765-2768.

Kitanidis, P. K. (1973), Introduction to Geostatistics, 249 pp., Cambridge Univ. Press, New York.

Ledwell, J. R., and A. Bratkovich (1995), A tracer study of mixing in the Santa Cruz Basin, J. Geophys. Res., 100(C10), 20,681-20,704.

Ledwell, J. R., A. J. Watson, and C. S. Law (1998), Mixing of a tracer in the pycnocline, J. Geophys. Res., 103(C10), 21,499-21,529.

Lentz, S., K. Shearman, S. Anderson, A. Plueddemann, and J. Edson (2003), Evolution of stratification over the New England shelf during the Coastal Mixing and Optics study, August 1996 to June 1997 , J. Geophys. Res., 108(C1), 3008, doi:10.1029/2001JC001121.

Lueck, R. G. (1990), Thermal inertia of conductivity cells: Theory, J. Atmos. Oceanic Technol., 7(5), 741-755.
Lueck, R. G., and J. J. Picklo (1990), Thermal inertia of conductivity cells: Observations with a Sea-Bird cell, J. Atmos. Oceanic Technol., 7(5), $756-768$

MacKinnon, J. A., and M. C. Gregg (2003), Mixing on the late-summer New England shelf: Solibores, shear and stratification, J. Phys. Oceanogr., 33, 1476-1492.

Munk, W. H. (1981), Internal waves and small-scale processes, in Evolution of Physical Oceanography, edited by B. A. Warren and C. Wunsch, pp. 264-291, MIT Press, Cambridge, Mass.

Oakey, N. S., and B. Greenan (2004), Mixing in a coastal environment: 2. A view from microstructure measurements, J. Geophys. Res., C10014, doi:10.1029/2003JC002193.

Osborn, T. R. (1980), Estimates of the local rate of vertical diffusion from dissipation measurements, J. Phys. Oceanogr., 10, 83-89.

Polzin, K., J. Toole, and R. Schmitt (1995), Finescale parameterizations of turbulent dissipation, J. Phys. Oceanogr., 25, 306-328.

Rehmann, C. R., and T. F. Duda (2000), Diapycnal diffusivity inferred from scalar microstructure measurements near the New England shelf/slope front, J. Phys. Oceanogr., 30, 1354-1371.

Rippeth, T. P., and M. E. Inall (2002), Observations of the internal tide and associated mixing across the Malin Shelf, J. Geophys. Res., 107(C4), 3028, doi:10.1029/2000JC000761.

Sandstrom, H., and N. Oakey (1995), Dissipation in internal tides and solitary waves, J. Phys. Oceanogr., 25, 604-614.

Shaw, W. J., J. H. Trowbridge, and A. J. Williams III (2001), Budgets of turbulent kinetic energy and scalar variance in the continental shelf bottom boundary layer, J. Geophys. Res., 106(C5), 9551-9564.

Smart, P. L., and I. M. S. Laidlaw (1977), An evaluation of some fluorescent dyes for water tracing, Water Resour. Res., 13, 15-33.

Sosik, H. M., R. E. Green, W. S. Pegau, and C. S. Roesler (2001), Temporal and vertical variability in optical properties of New England shelf waters during late summer and spring, J. Geophys. Res., 106(C5), 9455-9472.

Sundermeyer, M. A., and J. R. Ledwell (2001), Lateral dispersion over the continental shelf: Analysis of dye-release experiments, J. Geophys. Res., 106(C5), 9603-9622.

Yoshida, J., and N. S. Oakey (1996), Characterization of vertical mixing at a tidal-front on Georges Bank, Deep Sea Res., 43, 1713-1744.

T. Duda, Applied Ocean Physics and Engineering Department, Woods Hole Oceanographic Institution, Mail Stop 11, Woods Hole, MA 02543 1053,USA. (tduda@whoi.edu)

J. R. Ledwell, Applied Ocean Physics and Engineering Department, Woods Hole Oceanographic Institution, Mail Stop 12, Woods Hole, MA 02543-1053, USA. (jledwell@whoi.edu)

H. E. Seim, Marine Sciences Department, University of North Carolina, CB 3300, 12-7 Venable Hall, Chapel Hill, NC 27599, USA. (hseim@ email.unc.edu)

M. A. Sundermeyer, School for Marine Science and Technology, University of Massachusetts Dartmouth, 706 Rodney French Boulevard, New Bedford, MA 02744-1221, USA. (msundermeyer@umassd.edu) 